\author{
UNIVERSIDADE DE SÃO PAULO \\ FACULDADE DE ODONTOLOGIA DE BAURU
}

RAQUEL CAROLINE FERREIRA LOPES

Caracterização dos Potenciais Evocados Auditivos Corticais em indivíduos com longo tempo de uso do implante coclear 

RAQUEL CAROLINE FERREIRA LOPES

\title{
Caracterização dos Potenciais Evocados Auditivos Corticais em indivíduos com longo tempo de uso do implante coclear
}

\author{
Dissertação apresentada à Faculdade de \\ Odontologia de Bauru da Universidade de São Paulo \\ para obtenção do título de Mestre em Ciências do \\ Programa de Pós Graduação em Fonoaudiologia. \\ Área de concentração: Processos e Distúrbios da \\ Comunicação \\ Orientadora: Profa. Dra. Kátia de Freitas Alvarenga
}

BAURU

2013 


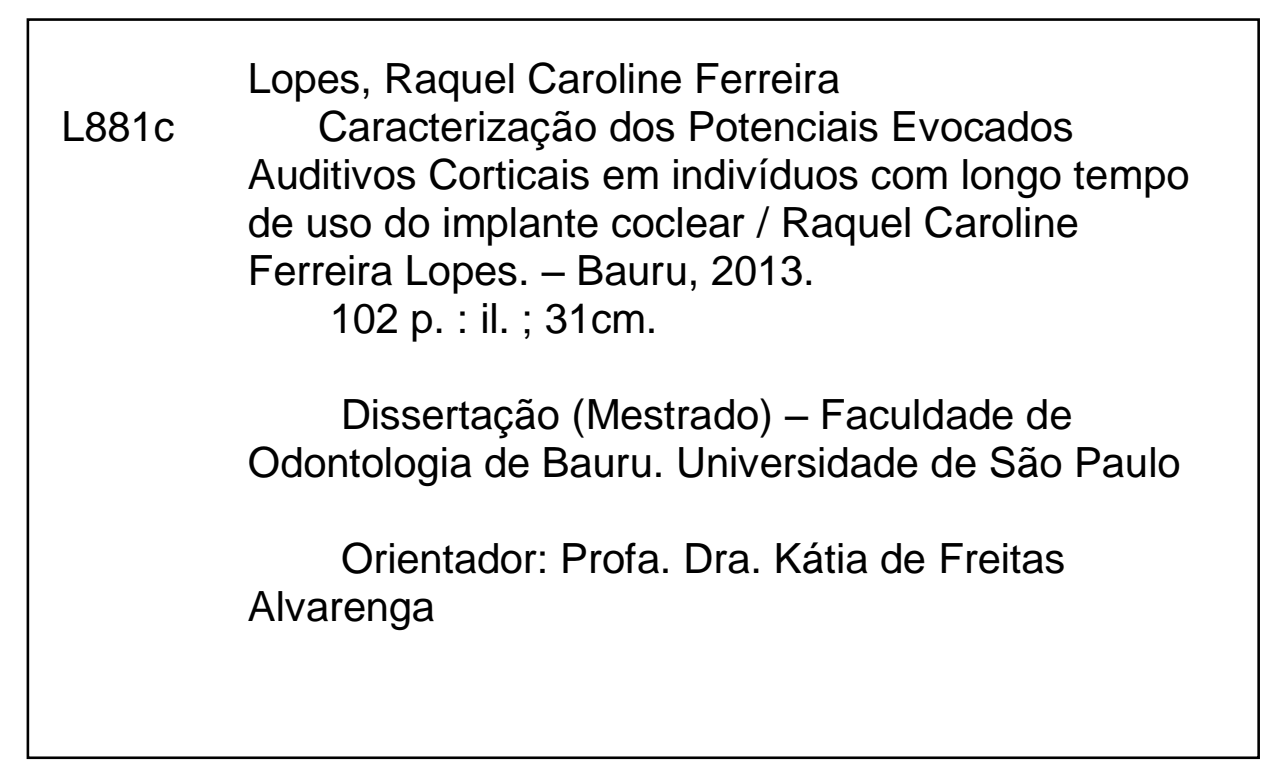

Autorizo, exclusivamente para fins acadêmicos e científicos, a reprodução total ou parcial desta dissertação/tese, por processos fotocopiadores e outros meios eletrônicos.

Assinatura:

Data:

Comitê de Ética da FOB-USP Protocolo no: 042/2011

Data: $27 / 04 / 2011$ 


\section{DEDICATÓRIA}

Dedico este trabalho aos meus amados pais, por todo amor e cuidado que sempre me proporcionaram. Por não terem medido esforços para fazer o melhor por mim, dedicando suas vidas à minha educação e formação. Sempre presentes para me socorrer no que fosse preciso. Eles, meus primeiros e eternos mestres, por me ensinarem os caminhos em que eu deveria andar, preparando-me para a vida.

Pai, obrigada pelo incentivo para continuar, em sempre fazer o meu melhor em tudo. Obrigada pelo apoio nos muitos anos longe de casa, pelas visitas, pela sua presença, por seu grande amor.

Mãe, obrigada por me transmitir o amor por lecionar, por me incentivar a leitura, por exigir que eu fosse a melhor em tudo o que eu fizesse, por me apoiar em minhas decisões e acompanhar essa jornada de estudos. Obrigada por ser meu exemplo, demonstrando o quanto você é aplicada em seus estudos e como é vencedora em tudo. Obrigada pelo seu grande amor.

Dedico este trabalho aos mestres da minha vida, obrigada por tudo! Sem vocês nada disto seria possível! Amo vocês! 



\section{AGRADECIMENTOS ESPECIAIS}

Agradeço a Deus por tudo que Ele é, por tudo que Ele fez em minha vida, por me presentear com a vida, por cuidar de mim em todos os momentos, por me fortalecer, por cuidar de cada detalhe, meu Amigo, meu Pai, meu Senhor, meu Salvador.

À Profa. Dra. Kátia de Freitas Alvarenga, pela confiança em mim depositada, por me despertar o interesse pela vida acadêmica, pelos momentos dispensados com as orientações acadêmicas, profissionais e pessoais, por me auxiliar em todos os momentos e por vivenciar, comigo, os momentos de inquietação frente às questões a serem respondidas. Por sua valiosa contribuição para minha formação, sempre ensinando com muito entusiasmo e amor. Meus sinceros agradecimentos.

Ao meu amado noivo Bruno Fontanelli, por estar ao meu lado em todas as situações, me dando-me apoio, motivação, carinho e amor. Por ouvir as minhas angústias sempre com paciência e disposição para ajudar. Pela confiança e respeito adquiridos durante esses anos de cumplicidade e amor. Obrigada por me tornar muito mais feliz, mas muito mais feliz. Você é um presente de Deus na minha vida.

À Profa. Dra. Adriane Lima Mortari Moret, pelo auxílio concedido nas discussões para análise dos dados, pelos conhecimentos partilhados, pela compreensão e orientações nos momentos de dúvidas e preocupações.

Ao meu amado irmão Hatus, pelo companheirismo, amor, amizade e todo o apoio que me deu em minha caminhada.

Às minhas avós Cleide e Maria, meu avô Samuel, meus tios queridos e meus primos Renan, Rafael e Júlia que sempre torceram e oraram por mim e compreenderam os meus momentos de ausência em função do caminho que optei por seguir. 



\section{AGRADECIMENTOS}

À Faculdade de Odontologia de Bauru, Universidade de São Paulo, por me proporcionar a base e extensão da minha formação acadêmica e profissional, com aparato técnico e científico de excelência.

À coordenadora do Programa de Pós-Graduação em Fonoaudiologia, Profa. Dra. Alcione Ghedine Brasolotto e à vice-coordenadora Profa. Dra. Kátia de Freitas Alvarenga, por toda dedicação, visando sempre à qualidade do Programa.

À coordenadora do Centro de Pesquisas Audiológias do HRAC/USP, Profa. Dra. Maria Cecília Bevilacqua, por seu engajamento em propagar o nome da Fonoaudiologia, em visar ao crescimento e aperfeiçoamento, por seu exemplo de luta e determinação.

À Profa. Dra. Maria Inês Pegoraro-Krook, chefe do Departamento de Fonoaudiologia da FOB/USP e chefe anterior, quem vivenciou todos os momentos durante o decorrer do mestrado Profa. Dra. Mariza Ribeiro Feniman.

À Fundação de Amparo a Pesquisa de São Paulo/FAPESP, pela bolsa concedida e todo apoio em vários momentos de minha carreira.

A cada criança, por participar da casuística deste trabalho, com sua família, permitindo que os resultados de sua avaliação fossem aqui publicados e contribuindo, assim, para o avanço da Audiologia no Brasil.

Ao Prof. Dr. Manoel Henrique Salgado, por seu respeito, compreensão, profissionalismo e pelo excelente trabalho no manejo estatístico dos dados obtidos.

Ao Prof. Dr. Orozimbo Alves Costa Filho e à Profa. Dra. Maria Cecília Bevilacqua, pelo auxílio concedido nas discussões para análise dos dados, pelo apoio nos momentos de dúvida e de preocupações.

Aos professores do Departamento de Fonoaudiologia da FOB/USP, por seus ensinamentos durante toda a minha formação acadêmica. 
Aos funcionários do Departamento de Fonoaudiologia da FOB/USP, Claudia, Daniele, Éliton, Karina e Renata pela costumeira ajuda, com prontidão e atenção.

Aos funcionários do Centro de Pesquisas Audiológicas do HRAC/USP, em especial à Rosemeire, Edilene, Dimas, Marli e Mari e às fonoaudiólogas Elisabete, Leandra, Cíntia e Luzia pela disposição em ajudar sempre no que foi preciso.

Aos funcionários da pós-graduação, pela disposição e paciência em todas as orientações.

Aos funcionários do Serviço de Biblioteca e Documentação da FOB/USP, pelo trabalho fundamental realizado com tanta dedicação e atenção.

Às fonoaudiólogas que integraram em algum momento a Clínica de Audiologia Infantil: Fernanda Zucki, Raquel Agostinho, Juliana, Eliene, Leticia, Raquel Amorim, Josilene, Elisne, Natalia, Flávia, Fernanda Granço, Luciana Oliveira, Luciane Mariotto, Fabiana, Tatiana, Profa. Dra. Andréa Lopes, Profa. Dra. Lilian Corteletti, pela convivência, pela rica troca de experiências e pelo apoio.

Aos funcionários da Clínica de Fonoaudiologia da FOB/USP, em especial à Karen, Lucas, Thiago, Sidney e Lívia, pela atenção e carinho.

Aos meus queridos amigos da turma de mestrado de 2011 e 2012, em especial Camila Ribeiro, Maria Renata, Vanessa e Camila Corrêa por compartilharmos momentos de anseios, dúvidas e sucesso em nossa caminhada.

Às amigos Daise, Lincon, Vanice, Guto, Carmen, Guto, Reginaldo, Ester, Felipe, Milton, Lúcia, Valerie, David, Ryan, Shelly, Beatriz, Tati, Thiago e à Keld, minha irmã de coração, que tornaram meus dias mais leves e alegres.

A todos que direta ou indiretamente me ajudaram a chegar até aqui. 
"O amor é paciente, é benigno; o amor não arde em ciúmes, não se ufana, não se ensoberbece, não se conduz inconvenientemente, não procura os seus interesses, não se exaspera, não se ressente do mal; não se alegra com a injustiça, mas regozija-se com a verdade; tudo sofre, tudo crê, tudo espera, tudo suporta." 



\section{RESUMO}

As mudanças fisiológicas no sistema auditivo relacionadas à idade refletem nos potenciais evocados auditivos, sendo possível, assim, determinar a relação existente entre estas mudanças e 0 desenvolvimento das habilidades auditivas comportamentais. A percepção do som pode alterar o eletroencefalograma do humano ouvinte, e estas modificações podem ser extraídas deste registro, identificando os potenciais evocados auditivos, usados para descrever a resposta do sistema auditivo frente à estimulação. O implante coclear tem sido uma opção de sucesso para a reabilitação auditiva de crianças com perda auditiva de grau severo ou profundo; o uso do dispositivo por longo tempo pode alterar as respostas do sistema nervoso auditivo central para a estimulação elétrica por meio do implante coclear, uma vez que a literatura apresenta que a experiência com o implante coclear proporciona melhores resultados quanto à percepção da fala. $\mathrm{O}$ objetivo deste estudo foi identificar e verificar as características do componente $P_{1}$ dos potenciais evocados auditivos corticais em indivíduos com deficiência auditiva com longo tempo de uso do implante coclear e correlacioná-los com o desempenho da percepção da fala e, secundariamente, a outras variáveis relacionadas ao implante coclear. Participaram deste estudo 30 usuários de implante coclear que foram implantados na idade de dois a quatro anos, de ambos os sexos, com tempo de uso do dispositivo eletrônico variando entre seis a 14 anos. Foi pesquisado o componente $\mathrm{P}_{1}$ dos potenciais evocados auditivos corticais com o estímulo de fala /da/ e avaliada a percepção da fala com lista de sentenças. Os procedimentos foram realizados em campo livre. Como resultado, foi constatado que o componente $P_{1}$ foi registrado em todos os indivíduos avaliados, com valores médios latência em $131,87 \pm 34,46$ ms e amplitude $2,42 \pm 1,46 \mu \mathrm{V}$. Notou-se a ocorrência da redução da latência $(p=0539)$ e o aumento da amplitude $(p=0,297)$ do componente $P_{1}$, com ausência de correlação entre os grupos com menos e mais de 10 anos do uso do dispositivo eletrônico. Ao analisar o desempenho na percepção da fala e as características do componente $\mathrm{P}_{1}$, pela pontuação comportamental, foi considerado como desempenho "bom" o escore $>54 \%$, e "ruim" $\leq 54 \%$, e posterior análise da média de latência do $P_{1}(p=0753)$ e da amplitude $(p=0,399)$ em ambos os grupos, não foi encontrada diferença estatisticamente significante. Deste modo, a presença do componente $\mathrm{P}_{1}$ em indivíduos usuários de implante coclear demonstra que o 
implante coclear restaura a capacidade de ouvir. O padrão maturacional do potencial cortical segue o curso semelhante ao da criança ouvinte, porém com um atraso na latência e diminuição da amplitude. Após longo período de uso do implante coclear, o componente $\mathrm{P}_{1}$ não é um preditor único do desempenho na percepção de fala.

Palavras-chave: Potenciais Evocados Auditivos. Implante Coclear. Efeito Idade. 


\section{ABSTRACT \\ Characterization of Cortical Auditory Evoked Potentials in individuals with long-term use of cochlear implants}

The physiological changes in the auditory system based on age reflect in the auditory evoked potentials, thus, it is possible to determine that a relationship exists between these changes and the development of auditory skills. The perception of sound can change the electroencephalogram of the human listener, and these modifications can be extracted from this record, identifying the auditory-evoked potentials used to describe the response of the front auditory system to stimulations. The cochlear implant has been a successful option for hearing correction in children with moderate or serious hearing loss; the long-term use of the device can change the responses of the central nervous auditory system for the electric stimulation through the cochlear implant once the literature shows that the experience with the cochlear implant provides good speech perception results. The objective of this study was to identify and verify the characteristics of the $P_{1}$ component of the cortical auditory evoked potentials in hearing-impaired individuals with long-term use of the cochlear implant and correlate them with speech development, and secondarily, other variables related to the cochlear implant. Thirty (30) cochlear implant users, both male and female, implanted between the ages of two and four years old and use of the electronic device for the time period between six and 14 years, participated in this study. The $\mathrm{P}_{1}$ component of the cortical auditory evoked potentials was studied with speech stimulation and speech perception evaluated with a list of sentences. The procedures were evaluated in an open environment. As a result, it was found that the $\mathrm{P}_{1}$ component was recorded in each of the evaluated, with average latent values of $31,87 \pm 34,46 \mathrm{~ms}$ and amplitude of $2,42 \pm 1,46 \mu \mathrm{V}$. The occurrence of latency reduction $(p=0,539)$ and the increase in amplitude $(p=0,297)$ of the $P_{1}$ component were noted, with the absence of correlation between the groups with less and more than 10 years of use of the electronic device. When analyzing the effort in speech perception and the characteristics of the $\mathrm{P}_{1}$ component by the behavioral points, the score of $>54 \%$ was considered "good", and $\leq 54 \%$ was "poor", and the later analysis of the latent values of the $P_{1}$ component $(p=0,753)$ and the amplitude $(p=0,399)$ in both groups, a statistically significant difference was not found. Thus, the presence of 
the $\mathrm{P}_{1}$ component in individual cochlear implant users shows that the cochlear implant restores the capacity to hear. The standard maturity potential of the cortical closely follows that of a hearing child, but with a delay in latency and decrease in amplitude. After a long period of cochlear implant use, the $\mathrm{P}_{1}$ component is not a lone predictor of speech perception performance.

Key words: Evoked Potentials, Auditory. Cochlear Implantation. Age Effect. 


\section{LISTA DE ILUSTRAÇÕES}

\section{- FIGURAS}

Figura 1 - Exemplo de colocação dos eletrodos para a pesquisa dos Potenciais Evocados Auditivos Corticais.

Figura 2 - Exemplo de colocação dos eletrodos para a pesquisa dos Potenciais Evocados Auditivos Corticais em um indivíduo do grupo experimental.

Figura 3 - Registro do complexo $\mathrm{P}_{1}-\mathrm{N}_{1}-\mathrm{P}_{2}$ dos potenciais evocados auditivos corticais em duas apresentações de 150 promediações na intensidade de $70 \mathrm{~dB}$ NA e uma em $0 \mathrm{~dB}$ NA, obtido no indivíduo 8, usuário de IC Nucleus 24k, processador Freedom, estratégia $A C E$, implantado com dois anos e oito meses, com tempo de uso do implante coclear de nove anos

Figura 4 - Registro dos potenciais evocados auditivos corticais do indivíduo sete do grupo experimental, com idade auditiva de 14 anos, implantado com 3 anos e 4 meses, usuário do implante coclear Nucleus 24k, processador Freedom, estratégia ACE, com oito anos de uso

\section{- GRÁFICOS}

Gráfico 1 - Comportamento da latência (ms) do componente $P_{1}$, de acordo com as idades, para os grupos controle e experimental.

Gráfico 2 - Comportamento da amplitude $(\mu \mathrm{V})$ do componente $P_{1}$, de acordo com as idades, para os grupos controle e experimental.

Gráfico 3 - Análise estatística da latência $(\mathrm{ms})$ do componente $P_{1}$ considerando dois grupos, de acordo com a idade na cirurgia ( $\leq$ 3,5 anos e $>3,5$ anos)

Gráfico 4 - Análise estatística da amplitude $(\mu \mathrm{V})$ do componente $P_{1}$ considerando dois grupos, de acordo com a idade na cirurgia ( $\leq$ 3,5 anos e $>3,5$ anos) 
Gráfico 5 - Análise estatística da latência (ms) do componente $P_{1}$ considerando dois grupos, de acordo com o tempo de uso do dispositivo ( $<10$ anos e $\geq 10$ anos)

Gráfico 6 - Análise estatística da amplitude $(\mu \mathrm{V})$ do componente $P_{1}$ considerando dois grupos, de acordo com o tempo de uso do dispositivo ( $<10$ anos e $\geq 10$ anos)

Gráfico 7 - Análise estatística da latência (ms) do componente $P_{1}$ em dois grupos, de acordo com o desempenho no teste de percepção da fala com sentenças

Gráfico 8 - Análise estatística da amplitude $(\mu \mathrm{V})$ do componente $P_{1}$ em dois grupos, de acordo com o desempenho no teste de percepção de fala com sentenças

Gráfico 9 - A análise estatística do desempenho, nos testes de percepção da fala, com sentenças, considerando dois grupos, de acordo com o tempo de uso do implante coclear $(<10$ anos e $\geq 10$ anos)

\section{- QUADROS}

Quadro 1 - Estratégia de busca utilizada nas bases de dados. 


\section{LISTA DE TABELAS}

Tabela 1 - Caracterização da casuística do grupo experimental quanto ao tipo de implante coclear, processador de fala, estratégia de processamento do sinal acústico, idade de ativação do dispositivo, idade cronológica e tempo de uso em anos................................... 63

Tabela 2 - Análise descritiva do tempo de uso, idade na cirurgia, percepção da fala, latência (ms) e amplitude $(\mu \mathrm{V})$ do componente $\mathrm{P}_{1}$ para os grupos experimental e controle. 



\section{LISTA DE ABREVIATURA E SIGLAS}
AASI Aparelho de Amplificação Sonora Individual
ACE Advanced Encoder Conversion
BVS Biblioteca Virtual em Saúde
CIS Continuous Interleaved Sample
cm Centímetro
CPA Centro de Pesquisas Audiológicas
DA Deficiência Auditiva
dB NA Decibel Nível de Audição
dP Desvio padrão
EEG Eletroencefalograma
GC Grupo controle
GE Grupo experimental
HINT Hearing In Noise Test
HRAC Hospital de Reabilitação de Anomalias Craniofaciais
$\mathrm{Hz} \quad$ Hertz
IC Implante Coclear
IEL Instituto de Estudos da Linguagem
LAFAPE Laboratório de Fonética e Psicolinguística
ms Milissegundos
ns Não Significante
PBK Phonetically Balanced Kindergarten
PEA Potencial Evocado Auditivo
PEAC Potencial Evocado Auditivo Cortical
PEALL Potencial Evocado Auditivo de Longa Latência
pps Pulsos por segundo
TANU Triagem Auditiva Neonatal Universal
TPF Teste de Percepção da Fala
UNICAMP Universidade Estadual de Campinas
USP Universidade de São Paulo 



\section{LISTA DE SÍMBOLOS}

$\begin{array}{ll}\mu \mathrm{V} & \text { Microvolt } \\ \mathrm{Cz} & \text { Coronal, linha mediana } \\ \mathrm{kHz} & \text { Quilohertz } \\ \mathrm{M} 1 & \text { Mastoide esquerda } \\ \mathrm{M} 2 & \text { Mastoide direita }\end{array}$





\section{SUMÁRIO}

1 INTRODUÇÃO 29

1.1 JUSTIFICATIVA 32

2 REVISÃO DE LITERATURA 35

3 PROPOSIÇÃO 49

4 MATERIAL E MÉTODO 53

4.1. SELEÇÃO DA CASUÍSTICA 55

4.2. CASUÍSTICA 56

4.3. METODOLOGIA 56

4.3.1. Potenciais Evocados Auditivos Corticais 56

4.3.2. Avaliação da Percepção da Fala 59

4.4. ANÁLISE ESTATÍSTICA 60

5 RESULTADOS 61

5.1. MORFOLOGIA DOS REGISTROS 64

5.2. ANÁLISE INFERENCIAL 64

6 DISCUSSÃO

7 CONCLUSÕES 79

REFERÊNCIAS 83

APÊNDICES 93

$\begin{array}{ll}\text { ANEXOS } & 97\end{array}$ 

1 Introdução 

1 INTRODUÇÃO

O implante coclear (IC) tem sido uma opção de sucesso para a reabilitação auditiva de crianças com perda auditiva de grau severo ou profundo que não se beneficiam da amplificação tradicional, pois permitem que a pessoa com deficiência auditiva (DA) aproprie-se da linguagem oral. Resultados obtidos nos primeiros anos de uso do IC em crianças têm sido amplamente discutidos na literatura, demonstrando os benefícios na linguagem receptiva e expressiva; no entanto, constata-se uma variabilidade nos resultados em crianças.

O desenvolvimento normal das estruturas corticais auditivas é prérequisito para a aquisição das habilidades auditivas comportamentais, fator que vem sendo amplamente estudado com o acompanhamento das crianças que receberam o IC precoce e tardiamente; no entanto, pouco se sabe da estimulação cortical com o IC após um longo tempo de uso do dispositivo.

$O$ registro dos potenciais evocados auditivos corticais (PEAC) permite a visualização da estimulação cortical com a estimulação auditiva do IC, demonstrando o redirecionamento das estruturas centrais para a sua função primária.

Diante do exposto, surgiu o interesse em verificar a resposta do sistema nervoso auditivo central para a estimulação elétrica por meio do IC ao longo do tempo de uso do dispositivo, uma vez que a literatura apresenta que a experiência com o IC proporciona melhores resultados quanto à percepção da fala, assim como correlacionar os achados dos PEAC com o desempenho da percepção de fala.

A Sessão de Implante Coclear - Centro de Pesquisas Audiológicas (CPA) do Hospital de Reabilitação de Anomalias Craniofaciais (HRAC) da Universidade de São Paulo (USP) realiza cirurgias há mais de vinte anos, iniciando o programa em 1990; desde então, mais de 1000 cirurgias foram realizadas pelo serviço de saúde auditiva. $O$ centro se destaca pela intervenção em crianças com a realização de cirurgias e no acompanhamento periódico dessas crianças, permitindo, assim, a inserção de procedimentos de avaliação nesses indivíduos que foram submetidos à cirurgia há um longo tempo. 


\subsection{JUSTIFICATIVA}

O mecanismo da audição compreende a transdução do estímulo acústico em impulsos neurais pela orelha interna, a transmissão desses impulsos por uma rede neural até o córtex cerebral e o registro perceptual com posterior elaboração cognitiva do sinal acústico (BONALDI, 2011). Desta forma, a mensagem sonora torna-se consciente e compreensível. Ao contrário da porção periférica do sistema auditivo (cóclea), as estruturas centrais (nervo, tronco encefálico e córtex) passarão pelo processo maturacional, ocorrendo desde primeiros os meses de vida até a adolescência, decorrente da estimulação auditiva.

A função do IC é converter a energia sonora em baixos níveis de corrente elétrica, para estimulação direta das fibras nervosas, remanescentes do nervo auditivo (YOON, 2011), ultrapassando as células ciliadas lesionadas na orelha interna (BEITER e SHALLOP, 1998; COSTA FILHO, 1998).

Estudos foram desenvolvidos para avaliar os resultados da percepção auditiva dos sons da fala e da aquisição da linguagem oral em crianças submetidas à cirurgia de IC, sendo constatados resultados excelentes a outros com desempenho limitado (MOOG; GEERS, 1999; GEERS, 2004; NASCIMENTO et al., 2005; DESJARDIN et al., 2009; SPENCER; TOMBLIN, 2009; DAVIDSON et al., 2011; PISONI et al., 2012; GANEK et al., 2012). Os principais aspectos apontados para justificar estes resultados são a idade na cirurgia, o tempo de privação sensorial auditiva, tempo de uso do IC, processo terapêutico e envolvimento familiar (GEERS et al., 2002; ZWOLAN et al., 2004; MORET et al., 2007; HAYES et al., 2009; PETERSON et al., 2010; ANGELO et al., 2010; MARKMAN et al., 2011; CONWAY et al., 2011; BOONS et al., 2012; TANAMATI et al., 2012).

Após um período de privação sensorial, o sistema nervoso se reorganiza, com o restabelecimento da audição ocorre um redirecionamento das estruturas nervosas para sua função primária. Este redirecionamento representa a plasticidade do sistema nervoso auditivo, ou seja, a capacidade das estruturas auditivas responderem à estimulação mesmo após um período de privação sensorial que levou à reorganização cortical (PONTON et al., 2001; SHARMA et al., 2002; KELLY et al., 2005; WUNDERLICH et al., 2006; GILLEY et al., 2008; SHARMA et al., 2009; KRAL; SHARMA, 2011). Contudo, a plasticidade neural é mais intensa nos primeiros 
anos de vida, considerado o período sensível para a reabilitação auditiva (SHARMA et al., 2005), e diminui com a idade.

Desde que Davis (1939) descreveu que a percepção do som pode alterar o eletroencefalograma do humano ouvinte, e que estas modificações podem ser extraídas deste registro, inúmeros pesquisadores têm utilizado os potenciais evocados auditivos (PEA) para descrever a resposta do sistema auditivo frente à estimulação (SHALLOP, 1993; PONTON et al., 1996; GROENEN et al., 1996; EGGERMONT et al., 1997; KILENY et al., 1997; OKUSA et al., 1999; SHARMA et al., 2002; PANTEV et al., 2002; BEYNON et al., 2002; SHARMA et al., 2004; SINGH et al., 2004; GILLEY et al., 2005; SHARMA et al., 2005; KELLY et al., 2005; ROMAN et al., 2005; GORDON et al., 2005; BAUER et al., 2006; DORMAN et al., 2007; GIRAUD et al., 2007; MCNEILL et al., 2007; KRAL \& EGGERMONT, 2007; GORDON, 2008; GILLEY et al., 2008; BROWN et al., 2008; KURNAZ et al., 2009; MCNEILL et al., 2009; MARIAM et al., 2009; JOHNSON, 2009; FRIESEN et al., 2009; HANCOCK et al., 2010; KRAL \& SHARMA, 2011; ZHANG et al., 2011; CASTAÑEDA-VILLA et al., 2012).

Os PEA refletem, assim, a atividade elétrica gerada nas estruturas e vias do sistema auditivo (cóclea, nervo auditivo, tronco encefálico e cérebro) em resposta a uma estimulação acústica, caracterizada por uma sequência de picos positivos e negativos (SOUZA et al., 2010), fornecendo informações sobre a via e estruturas que foram ativadas, inclusive por meio da estimulação pelo IC.

Diferentemente dos PEA periféricos, a atividade elétrica gerada na porção cortical representa a soma da atividade neural originada de várias distintas fontes (NÄÄTÄNEN \& PICTON, 1987). Por causa da multiplicidade e complexidade das estruturas do sistema auditivo, existe pouco consenso dos precisos geradores dos PEAC, porém é descrita a participação do córtex auditivo primário e secundário, mesencéfalo, assim como as áreas de associação, como córtex centro parietal e lobo frontal, e áreas do cérebro envolvendo memória, como o hipocampo (LIËGEOIS-CHAUVEL et al., 1994; MCPHERSON, 1995; DEOUELL; BENTEN, 1998; CONE-WESSON; WUNDERLICH, 2003). Especificamente para o componente $\mathrm{P}_{1}$, os geradores neurais incluem o córtex auditivo primário (giro de Heschl), 0 hipocampo, plano temporal, região temporal lateral e possíveis regiões subcorticais. A latência emindivíduos adultos ouvintes normais é encontrada em torno de $50 \mathrm{~ms}$ 
após o início do estímulo e em crianças ouvintes normais por volta de $85 \mathrm{~ms}$ (GILLEY et al., 2005; VENTURA et al., 2009; AGOSTINHO-PESSE, 2011).

Alguns estudos em indivíduos normais apontaram que os valores de latência dos componentes $P_{1}$ e $N_{1}$ aproximam-se aos encontrados nos adultos, a partir dos 15 anos até os 20 anos (SHARMA, et al., 1997; MARIAM, et al., 2009), o que indica que o processo maturacional dos sítios geradores destes potenciais completa-se na segunda década de vida, o que pode explicar a diferença entre os valores de latência encontrados entre as crianças e adultos (VENTURA et al., 2009).

Assim, o componente $\mathrm{P}_{1}$ tem sido considerado um biomarcador do desenvolvimento das estruturas do sistema auditivo em crianças ouvintes ou deficientes auditivas usuárias de IC (SHARMA et al., 2002; SHARMA et al., 2004; PONTON et al., 1996), com exceção das crianças que receberam o IC em idades mais avançadas (SHARMA et al., 2005; GILLEY et al., 2008).

Dentro deste contexto, estudos foram realizados durante os primeiros anos de uso do IC, e demonstraram a correlação negativa da latência e amplitude dos PEAC com o desempenho da percepção da fala nas crianças usuárias de IC (BEYNON et al., 2002; MAURER et al., 2002; SHARMA et al., 2004; GORDON et al., 2005; KELLY et al., 2005; ROMAN et al., 2005; MCNEILL et al., 2007; GORDON et al., 2008; KURNAZ et al., 2009; MCNEILL et al., 2009).

Desta forma, a compreensão dos fatores neurobiológicos e cognitivos, que contribuem para um resultado favorável após o IC, permitiria a predição dos resultados esperados para um paciente (PETERSON et al., 2010), o que forneceria subsídios para maximizar os benefícios do IC. 
2 Revisão de Literatura 

2 REVISÃO DE LITERATURA

A revisão de literatura foi desenvolvida baseada nos princípios da revisão sistemática (COX, 2005), a fim de apresentar a bibliografia com alta evidência científica para o estudo.

Como parte da metodologia proposta, a busca pelos estudos baseou-se na seguinte pergunta: "Quais são as características quanto à latência e amplitude do componente $\mathrm{P}_{1}$ do PEAC, em indivíduos com longo tempo de uso do IC?".

A busca pelos artigos científicos foi realizada no Portal Cochrane da Biblioteca Virtual de Saúde (BVS) - endereço: http://cochrane.bvsalud.org/ e Biblioteca Virtual de Saúde (BVS) - endereço: http://regional.bvsalud.org/ e nas bases de dados Lilacs, Medline, Pubmed, Web of Science e Science Direct utilizando os descritores específicos, com atenção para aqueles que abordassem a temática e a não utilização de sinônimos ou subordinados. Para a definição dos descritores empregou-se o vocabulário estruturado e trilíngue DeCS/MesH Descritores em Ciências da Saúde criado pela BIREME. Pelo fato de existirem descritores com ampla abrangência e poucos relacionados ao assunto, estabeleceuse a utilização de termos para uma busca refinada.

Para a busca, não houve restrição quanto ao ano de publicação; portanto, foram analisados todos os estudos publicados até dezembro de 2012. Como critério de inclusão nesta pesquisa, estabeleceu-se que na metodologia pesquisada constassem informações sobre a metodologia, no caso, os PEAC e a casuística formada por indivíduos usuários de IC após um período de tempo.

Quadro 1 - Estratégia de busca utilizada nas bases de dados.

\section{Estratégia de busca}

"Evoked potentials, auditory" and "Cochlear implantation" and "Adaptation"

"Evoked potentials, auditory" and "Cochlear implantation" and "Time"

"Evoked potentials, auditory" and "Cochlear implantation" and "Age Effect"

"Auditory cortical event related potentials" and "Cochlear implantation" and "Time"

"Auditory cortical event related potentials" and "Cochlear implantation" and "Adaptation"

"Auditory cortical event related potentials" and "Cochlear implantation" and "Age Effect"

"Auditory event related potentials" and "Cochlear implantation" and "Time"

"Auditory event related potentials" and "Cochlear implantation" and "Adaptation"

"Auditory event related potentials" and "Cochlear implantation" and "Age Effect"

"Long latency auditory evoked potentials" and "Cochlear implantation" and "Time"

"Long latency auditory evoked potentials" and "Cochlear implantation" and "Adaptation"

"Long latency auditory evoked potentials" and "Cochlear implantation" and "Age Effect" 


\section{"Auditory cortex" and "Cochlear implantation" and "Time" \\ "Auditory cortex" and "Cochlear implantation" and "Adaptation" \\ "Auditory cortex" and "Cochlear implantation" and "Age Effect" \\ "Acoustic stimulation" and "Cochlear implantation" and "Time" \\ "Acoustic stimulation" and "Cochlear implantation" and "Adaptation" \\ "Acoustic stimulation" and "Cochlear implantation" and "Age Effect" \\ "Response latency" and "Cochlear implantation" and "Time" \\ "Response latency" and "Cochlear implantation" and "Adaptation" \\ "Response latency" and "Cochlear implantation" and "Age Effect"}

Com os resultados da busca, seguindo as estratégias descritas no Quadro 1, excluindo os estudos repetidos, foram encontrados na literatura específica os estudos descritos a seguir:

Ponton et al. (1996) estudaram os efeitos da privação sensorial sobre a maturação do sistema auditivo humano, em oito adultos e 31 crianças, com audição normal, e seis adultos e 12 crianças usuárias de IC. O critério de inclusão foi apresentar considerável ganho no reconhecimento de fala com o IC. A latência do componente $\mathrm{P}_{1}$ foi analisada em função da idade, sendo que três grupos de crianças implantadas foram definidos baseados na duração da privação auditiva: 1,1 anos, variando de cinco meses para dois anos e dois meses (curto período); 4,9 anos, variando de 3,5 a 6 anos (médio período); 8,4 a 8,10 anos (longo período). Como resultado, obteve-se que a taxa de maturação é igual entre as crianças ouvintes e crianças implantadas, com diminuição da latência com a idade, o que sugere que a estimulação elétrica do nervo auditivo é capaz de restaurar o tempo de curso normal da maturação para, pelo menos alguns, se não todos, aspectos da função auditiva cortical, mesmo após um extenso período de privação. Contudo, o processo maturacional ocorre com atraso de acordo com o tempo de privação sensorial.

Ponton \& Eggermont (2001) resgistraram os PEAC $\left(P_{1}-N_{1}-P_{2}\right)$ em 118 indivídos ouvintes na faixa etária de cinco a 20 anos, e em nove usuários de IC com tempo médio de privação sensorial de 3,6 anos (2,5 a 5,6 anos), que apresentavam de moderado para bom desempenho no reconhecimento da linguagem oral. Os individuos usuários de IC foram avaliados longitudinalmente entre duas a oito sessões. Os achados indicaram que, mesmo após muitos anos de uso do IC, os PEAC dos indivíduos em idade jovem mantêm-se muito diferentes daqueles indivíduos ouvintes de mesma idade. A latência do pico $P_{1}$ mantém-se prolongada e 
a amplitude mais larga em usuários com IC. Adicionalmente, o pico $\mathrm{N}_{1}$ normal não aparece em todas as crianças implantadas, o que leva a uma maturação anormal dos potenciais, devido a uma persistente imaturidade das camadas axoniais superficiais, com consequente efeito negativo na geração do $N_{1 b}$. Desta forma, os PEA registrados nas crianças com IC indicaram que existe significante atraso maturacional e alteração neural, mesmo para eventos sensoriais simples, como o estímulo clique utilizado neste estudo. Entretanto, a estimulação do sistema auditivo pelo IC é suficiente para restaurar alguns aspectos da maturação, pelo menos até cerca dos 12 anos de idade. O processo cortical de sensação e percepção, que apresenta alterações refletidas nos PEAC de crianças implantadas, está relacionado com o desenvolvimento observado dos processos corticais de mais alta complexidade, envolvendo a produção e percepção da linguagem oral.

Singh et al. (2004) realizaram um estudo com os potenciais evocados auditivos de longa latência (PEALL) com estímulo de fala, com o objetivo de identificar se estes procedimentos eletrofisiológicos poderiam ser utilizados para categorizar os pacientes usuários de IC quanto ao bom e pobre desempenho. $O$ estudo foi realizado em indivíduos usuários de IC com idade de sete a 17 anos, nos quais 27 foram implantados na orelha direita e oito na orelha esquerda. Dois indivíduos apresentavam perda auditiva pós-lingual e 33 pré-lingual, dos quais, 26 eram congênitas e sete progressivas. O tempo de uso do IC variou de um a dez anos. Para a análise, compararam a ocorrência, latência e amplitude dos componentes $\mathrm{P}_{1}$ e $\mathrm{N}_{2}$ com o resultado da avaliação comportamental que incluiu a categoria do desempenho auditivo e classificação de inteligibilidade de fala. Os resultados revelaram que a maioria apresentava respostas consistentes, demonstraram um importante componente positivo $\left(P_{1}\right)$, seguido por uma negatividade $\left(\mathrm{N}_{2}\right)$, obtido em 30 dos 35 indivíduos. Contudo, houve ausência do componente $\mathrm{N}_{1}$ em todos os pacientes. A latência do componente $\mathrm{P}_{1}$ reduziu com o tempo de uso do IC, com correlação negativa estatisticamente significante. Portanto, os autores concluíram que o IC não pode substituir a audição normal ao considerar a maturação das estruturas auditivas, mesmo em indivíduos implantados após 15 anos, idade do indivíduo com perda auditiva adquirida com mais idade neste estudo. Além disso, a maturação das vias corticais que dão origem a $P_{1}$ não parecem estar relacionadas à proficiência na linguagem receptiva e expressiva, uma vez que 
nenhum padrão de maturação foi observado quando comparada à latência de $P_{1}$ com escore comportamental.

Gordon et al. (2008) realizaram um estudo com 16 indivíduos com tempo de uso do IC entre dois a 15 anos, submetidos à cirurgia com idades entre três a 14 anos. Foi realizada a pesquisa do PEAC com o estímulo tone burst $(0,5 \mathrm{k}, 2 \mathrm{k}$ e $6 \mathrm{k}$ $\mathrm{Hz}$ ) e aplicado o teste Phonetically Balanced Kindergarten (PBK), que consiste em uma lista de palavras para avaliar a percepção de fala dos indivíduos, a qual foi classificada como ruim quando os resultados obtidos foram abaixo de $50 \%$, e bom com resultados acima de 50\%, para posterior comparação dos resultados. Nos indivíduos com resultados classificados como ruins, foi constatado um pico negativo seguido de um pico positivo com baixa amplitude e latência aumentada, caracterizando um complexo $\mathrm{P}_{1}-\mathrm{N}_{1}-\mathrm{P}_{2}$ imaturo. Por outro lado, naqueles com resultados classificados como bons, os componentes $\mathrm{P}_{1}$ e $\mathrm{P}_{2}$ foram semelhantes ao de ouvintes. Diferente de outros estudos que apresentaram a maturação do complexo $\mathrm{P}_{1}-\mathrm{N}_{1}-\mathrm{P}_{2}$ na idade de nove a 12 anos, foi observado o registro do complexo $\mathrm{P}_{1}-\mathrm{N}_{1}-\mathrm{P}_{2}$ em três crianças avaliadas com idade inferior a nove anos. Outro aspecto importante foi a ocorrência do componente $P_{2}$, sugestivo de ser um potencial melhor visualizado em crianças jovens. Concluíram com este estudo que as respostas da estimulação cortical em usuários de IC, quando comparadas aos ouvintes, apresentam morfologia diferente. No entanto, quando a latência do componente $\mathrm{P}_{1}$ foi analisada, considerando a percepção da fala, constatou-se que os indivíduos com desempenho bom apresentam valores de latência do componente $P_{1}$ semelhantes aos valores de latência de ouvintes. Já os indivíduos com escores mais baixos de percepção da fala apresentaram respostas corticais aquém dos ouvintes, ou seja, valores aumentados de latência dos PEAC.

Castañeda-Villa et al. (2012), em estudo de coorte, verificaram a reorganização do córtex auditivo em crianças com DA com estimulação elétrica proporciada pelo IC, por meio da análise da simetria inter-hemisférica do componente $\mathrm{P}_{1}$. Avaliaram longitudinalmente cinco crianças entre quatro e dez anos de idade, com perda auditiva profunda bilateral pré-lingual, destras, com IC à orelha direita, usuárias de Nucleus 24, com estratégia de estimulação Advanced Encoder Conversion (ACE), com uma largura de pulso de $25 \mathrm{~ms}$, e 5760 pps taxa de 
estimulação total. Todas as crianças foram incluídas em um programa de reabilitação pós-cirurgia de IC, o qual incluía o treinamento de diferentes habilidades, tais como ouvir, falar, leitura e linguagem. As crianças foram testadas em dois momentos após a implantação: a primeira avaliação foi realizada com

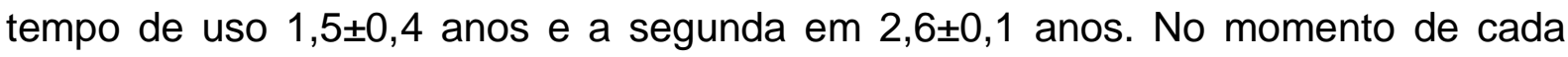
avaliação, o controle do volume do IC foi definido para um nível de maior conforto. $\mathrm{O}$ estímulo utilizado foi tone burst $(1000 \mathrm{~Hz})$, com nível de intensidade de $70 \mathrm{~dB}$ NA apresentado por um alto-falante posicionado a $1 \mathrm{~m}$ de distância à frente do indivíduo. Como resultado, observou-se que a região da resposta foi, predominantemente, parietal quando o dispositivo foi utilizado por menos de dois anos. Após este tempo, foi observado um redirecionamento da região estimulada para uma distribuição fronto-central contralateral ao IC, com exceção de um indivíduo, no qual não ocorreu modificação na região estimulada, fato que pôde ser justificado pelo pobre desempenho na terapia de reabilitação, tanto em termos de percepção do som quanto nas habilidades de fala, assim como a interrupção no uso do IC por mais de seis meses. $\mathrm{Na}$ análise dos dados obtidos, comentaram que o córtex auditivo imaturo influencia negativamente na percepção da fala e habilidades de produção de pacientes implantados. Ressaltarm, também, que o desempenho das crianças implantadas depende não somente da idade que foi realizada a cirurgia, mas também do ganho que o processador proporciona, assim como a sensibilidade do microfone e a influência dos níveis de conforto programados no IC. Há um alto índice de variabilidade de desempenho entre os indivíduos implantados, o que dificulta uma comparação generalizada; no entanto, o estudo longitudinal é viável para comparar a reorganização cortical em função do tempo pós-implantação.

Para complementação da literatura, optou-se para a realização da busca por estudos que abordassem os aspectos quanto à percepção da fala de indivíduos com deficiência auditiva usuários de IC por longo período, descritos a seguir:

Geers (2002) investigou os fatores que contribuem no desemprenho auditivo, fala, linguagem e leitura em crianças com DA pré-lingual quatro a seis anos depois da realização da cirurgia do IC multicanal. Para isso, realizou uma análise controlada dos resultados da criança com IC e características da família, para que fatores educacionais mais propícios para benefício do IC fossem identificados. A 
casuística incluiu 136 indivíduos com idade de oito a nove anos de idade, residentes nos Estados Unidos e Canadá, que foram implantados antes dos cinco anos com o Nucleus 22. Foram consideradas as variáveis: características da família quanto à educação, renda e tamanho da família; associadas ao IC foram incluídos a duração de uso do implante, duração do uso do processador de fala e estratégia; as variáveis usadas para avaliar o impacto da terapia foram o número de horas de terapia, a experiência clínica, que foi analisada com o nível de experiência com crianças com DA e com crianças usuárias de IC, e a participação dos pais na terapia. Quanto ao ensino, foram pesquisadas a classe em que estavam inseridos e o modo de comunicação em sala de aula. Foi observado que os resultados do IC foram intensamente associados ao quociente de inteligência não verbal, as características do IC e ao uso da comunicação oral. Concluiu, com este estudo, que as crianças que foram implantadas antes dos cinco anos de idade recebem a informação auditiva em um momento crucial para o desenvolvimento da fala e linguagem. À medida que a criança passa a usar esta informação para alcançar a fala, linguagem e leitura sofre interferência por uma série de fatores: que a criança traz para o ambiente de aprendizagem (inteligência não verbal); aqueles que são fornecidos pelo próprio IC, pois os benefícios de uma melhor tecnologia foram evidentes neste estudo, assim como um mapa bem ajustado refletiu uma gama de alcance dinâmica, contribuindo substancialmente com as características de sonoridade; e os que são fornecidos pelos pais e profissionais no programa de reabilitação da criança, já que a ênfase educacional na comunicação auri-oral foi considerada a variável mais importante para o desenvolvimento auditivo e da linguagem oral do que qualquer outro fator de reabilitação avaliado, pois a utilização de comunicação por libras com crianças implantadas não promoveu o desenvolvimento de habilidades auditivas e de fala.

Moret et al. (2007) estudaram o desempenho de audição e de linguagem oral de crianças portadoras de DA neurossensorial profunda bilateral pré-linguais, usuárias de IC, nos seguintes aspectos: idade da criança na época da realização da pesquisa, tempo de privação sensorial auditiva, tempo de uso do dispositivo, tipo de IC, estratégia de codificação de fala utilizada, grau de permeabilidade da família no processo terapêutico e estilo cognitivo da criança. Foram avaliadas 60 crianças quanto às categorias de audição e de linguagem. Os dados foram submetidos à 
análise estatística, com o enfoque nos aspectos psicossociais, considerando o estilo cognitivo da criança e o grau de permeabilidade da família. Os resultados demonstraram que 10 crianças estavam nas categorias auditivas iniciais 1 e 2; 23 alcançaram as categorias intermediárias 3 e 4; e 27 chegaram às categorias auditivas 5 e 6 , mais avançadas e mais difíceis. Portanto, as categorias auditivas intermediárias e avançadas foram alcançadas por mais da metade do grupo, o que é um resultado efetivo. Com relação à categoria de linguagem, 37 das 60 crianças alcançaram as categorias 3, 4 e 5 de linguagem, enquanto as 23 crianças restantes permaneceram na categoria 1 ou alcançaram a categoria 2, a qual representa um progresso mais limitado. A associação entre as categorias auditivas e de linguagem com o aspecto família exprime uma valiosa importância clínica no que se refere à quantidade e ao tipo de aconselhamento dispensado aos pais nas diversas fases do processo de realização do IC em crianças. Os aspectos associados estatisticamente significantes com o desempenho de audição e de linguagem oral foram: a idade da criança na avaliação, o tempo de privação sensorial auditiva, o tempo de uso do IC, o tipo de IC, a estratégia de codificação dos sons da fala e a permeabilidade da família. Os autores concluíram que o IC como tratamento de crianças com deficiência auditiva neurossensorial pré-lingual é altamente efetivo, embora complexo, devido à interação de variáveis que interferem no desempenho da criança, demonstrando a necessidade de novos estudos para a compreensão da complexidade da implantação em crianças pequenas.

Stuchi et al. (2007) traçaram um perfil de linguagem oral receptiva e expressiva em crianças usuárias de IC e verificaram a influência do tempo de privação sensorial na linguagem oral receptiva e expressiva dessas crianças. Para tanto, avaliaram 19 crianças usuárias de IC com DA pré-lingual, com tempo de uso do dispositivo variando de cinco anos a cinco anos e onze meses e média do tempo de privação sensorial de três anos. Foi utilizada a Reynell Developmental Language Scales (REYNELL \& GRUBER, 1990), composta pela Escala de Compreensão, de Expressão e suas Sub-Escalas: Estrutura, Vocabulário e Conteúdo. Os resultados revelaram correlação estatística entre o tempo de privação sensorial e a pontuação de Compreensão ( $p=-0,62 ; R=0,0044)$ e Conteúdo ( $p=-0,48 ; R=0,0348)$, com influência no tempo de privação na pontuação total ( $p=-0,53 ; R=0,0174)$. Tais dados sugerem que o perfil de linguagem das crianças implantadas com cinco anos 
de uso do IC seria próximo ao perfil de linguagem das crianças ouvintes com idade cronológica igual ao tempo de uso do IC. A linguagem compreensiva foi semelhante ao das crianças ouvintes de quatro anos de idade; e a linguagem expressiva foi semelhante ao das crianças ouvintes de cinco anos de idade. Concluíram os autores, que o perfil de linguagem oral das crianças implantadas há cinco anos apresentou-se desviante e não simplesmente atrasada em relação à normalidade.

Davidson et al. (2011) realizaram um estudo com 112 adolescentes implantados na idade de um ano e oito meses a cinco anos e quatro meses, com tempo de uso do dispositivo em média de 13 anos e três meses. Foram estudados os seguintes procedimentos de percepção da fala: Lexical Neighborhood Test, Bamford Kowal Bench Sentences, Children's Audio-Visual Enhancement Test, Consonant Production using McGarr Sentences, Test for Auditory Comprehension of Language, Peabody Picture Vocabulary Test-III. Foi constatada melhora significante no desempenho nos testes aplicados ao longo do tempo, o que sugere que a percepção da fala foi afetada pela experiência auditiva como também pela linguística, uma vez que responder corretamente a um teste de percepção da fala requer também o conhecimento lexical dos itens de estímulo e articulação da fala. Os avanços na tecnologia de implantes, juntamente com as orientações aos candidatos, assim como a revisão da seleção que inclui crianças com menos de dois anos de idade e com significativa audição residual pré-implante, podem resultar em níveis de percepção da fala ainda melhores.

Flexer et al. (2011) descreveram que a perda auditiva é, principalmente, um problema cerebral, e não uma questão de alteração na porção periférica do sistema auditivo. A tecnologia, por exemplo, IC e aparelho de amplificação sonora individual (AASI), é necessária para atingir o cérebro de uma criança com DA, a fim de criar uma estrutura neural de escuta, linguagem e alfabetização. $O$ cérebro requer uma grande dose de exposição auditiva e prática para desenvolver fortes conexões neurais que servem como uma plataforma para a aquisição de conhecimento. A tarefa do cérebro é criar um modelo ao nascimento, conforme o bebê aprende a gerenciar as ações necessárias para sobreviver e prosperar no mundo. A segunda etapa do desenvolvimento cortical é controlar a própria plasticidade, após o desenvolvimento de suas habilidades. Como os seres humanos 
são organicamente concebidos, os cérebros das crianças são tipicamente auditivos, com exposição a estímulos auditivos 24 horas por dia. No entanto, os cérebros das crianças com perda auditiva têm acesso ao som somente quando estão usando suas tecnologias, o que corresponde a muito menos de 24 horas por dia. Assim, limitar a função dos IC/AASI para vigília pode ter consequências importantes na plasticidade do cérebro e do amadurecimento das vias neurais. A exposição auditiva extensa cria uma base neurológica não só para a linguagem e a alfabetização, mas também para que ocorra o desenvolvimento cognitivo. Portanto, são necessários serviços integrados focados na intervenção auditiva projetados para oferecer milhares de horas de escuta e prática da língua aos bebês e crianças com perda auditiva que usam as tecnologias atuais.

Tanamati (2012) estudou o desempenho alcançado por adolescentes e jovens adultos com, no mínimo, dez anos de experiência com o $\mathrm{IC}$, em relação à audição e à inteligibilidade de fala, considerando o tipo de DA, o tempo de privação sensorial auditiva e o tipo de dispositivo. Participaram deste estudo, 61 adolescentes e jovens adultos com DA pré-lingual, que receberam diferentes tipos de IC nas idades de um a oito anos e três meses, com média de três anos e dez meses de idade. Reconhecimento da lista de palavras dissílabas, Teste HINT adaptativo e reconhecimento das sentenças HINT no silêncio e no ruído foram os procedimentos utilizados para avaliar o desempenho de audição. A inteligibilidade da fala dos participantes foi avaliada por dois profissionais sem experiência com DA, usando o método de transcrição e a escala de inteligibilidade de cinco pontos. Após 10 anos de experiência com o IC, 53 participantes (86,9\%) alcançaram habilidade de reconhecimento auditivo em conjunto aberto. Os resultados médios obtidos na lista de palavras dissílabas foram de 49,4\%; no teste HINT adaptativo no silêncio foi igual a $54,7 \mathrm{~dB}$ e no ruído, $10,7 \mathrm{~dB}$; nas sentenças $H I N T$ no silêncio foi de $54 \%$, e no ruído $33,3 \%$. Quanto à inteligibilidade de fala dos participantes, a média de acertos no método de transcrição foi igual a $76,2 \%$. Na escala de inteligibilidade, a pontuação média correspondeu a 3,3 pontos. Melhores desempenhos de audição no silêncio e no ruído foram correlacionados ao menor tempo de privação sensorial auditiva. Foi observada correlação entre o tipo de dispositivo utilizado e o desempenho de audição no ruído e o desempenho de inteligibilidade da fala. Usuários do dispositivo Nucleus 24 e Med-El apresentaram melhor desempenho de audição e de 
inteligibilidade de fala do que os usuários Nucleus 22. Após 10 anos de uso do IC, $82 \%$ das crianças implantadas com as primeiras gerações do dispositivo eletrônico desenvolveram habilidade de reconhecimento auditivo no ruído, e 90,1\% alcançaram fala inteligível. O desempenho de audição e de inteligibilidade de fala dos participantes foi influenciado pelo tempo de privação sensorial auditiva e pelo tipo de dispositivo eletrônico. Considerando os critérios contemporâneos de indicação cirúrgica em associação às novas estratégias de codificação de fala disponíveis nos dispositivos eletrônicos da atualidade, resultados promissores são esperados para a nova geração de crianças submetidas ao IC.

De acordo com Boons et al. (2012), embora as crianças com DA usuárias de IC sejam capazes de desenvolver competências linguísticas boas, a grande variabilidade nos resultados continua a ser uma preocupação significativa. Realizaram um estudo multicêntrico e retrospectivo, com enfoque no desenvolvimento da linguagem receptiva e expressiva de 288 crianças que receberam IC antes dos cinco anos de idade. Os objetivos deste estudo foram: avaliar as competências linguísticas em crianças com IC para estabelecer biomarcadores; estimar a idade ideal para a implantação a fim de proporcionar oportunidades máximas para a criança alcançar bons conhecimentos linguísticos; e adquirir conhecimento sobre as causas da variabilidade, a fim de definir recomendações para a otimização do processo de reabilitação de crianças com DA pré-lingual usuárias de IC. As medidas adotadas foram quocientes de linguagem nas escalas de Reynell Developmental Language Scales e Schlichting Expressive Language Test, com um, dois e três anos de uso do IC. Variáveis independentes preditivas foram principalmente fatores relacionados à criança, ambientais e auditivos. Foi realizada a análise de regressão múltipla para determinar a variância nos resultados de linguagem expressiva e receptiva atribuíveis a cada indicador, quando controlado por outras variáveis, tais como idade na primeira avaliação, sexo, etiologia, deficiências adicionais, estimulação contralateral, uso do AASI antes do IC, o multilinguismo, modo de comunicação e envolvimento dos pais. Os resultados demonstraram que as crianças implantadas antes da idade de dois anos tiveram um desempenho significativamente melhor em todos os testes do que as crianças que foram implantadas em idade mais avançada. A estimulação contralateral com o segundo IC ou o AASI associada à ausência de deficiências adicionais estavam 
relacionadas aos melhores resultados de linguagem oral. Os efeitos dos fatores ambientais aumentaram ao longo do tempo, observados nas avaliações realizadas com um, dois e três anos após a cirurgia. O multilinguismo na família foi consistentemente relacionado com a menor pontuação de linguagem, sendo que dois anos após a implantação, este fator foi acompanhado pelo baixo envolvimento dos pais no processo de reabilitação. Três anos após o IC, um terceiro fator ambiental surgiu, ou seja, filhos de pais que utilizavam a comunicação oral foram superiores aos filhos de pais que utilizavam a comunicação por linguagem de sinais. O melhor desempenho nas habilidades de linguagem receptiva e expressiva foi associado com a menor idade de cirurgia do IC, que deve ocorrer antes do segundo ano de vida. A presença de uma dificuldade de aprendizagem adicional foi um preditor de habilidades mais fracas de linguagem. Os resultados obtidos auxiliaram na compreensão das causas da variação nos resultados o que pode ajudar os pais e terapeutas a aperfeiçoar as circunstâncias para que as crianças implantadas adquiram a linguagem. 


3 Proposição 


3 PROPOSIÇÃo

Identificar e verificar as características do componente $\mathrm{P}_{1}$ dos PEAC, em indivíduos com DA, com longo tempo de uso do IC, e correlacioná-los com o desempenho da percepção da fala e, secundariamente, a outras variáveis relacionadas ao IC. 


Material e Métodos 




\section{MATERIAL E MÉTODOS}

O presente estudo foi realizado na Sessão de Implante Coclear CPA/HRAC - USP com a aprovação do Comitê de Ética em Pesquisa da Instituição, processo 042/2011 (ANEXO A e B) e financiamento da Fundação de Amparo à Pesquisa do Estado de São Paulo (processo número 2011/04698-7).

\subsection{SELEÇÃO DA CASUÍSTICA}

O grupo controle foi constituído por crianças avaliadas em estudo anterior desenvolvido no mesmo serviço (AGOSTINHO-PESSE, 2011). A avaliação audiológica foi realizada a fim de excluir as crianças com qualquer tipo de alteração auditiva e sem queixas de alteração no desenvolvimento global. A audiometria foi realizada com o equipamento Midmate 622 da Interacustics, em cabina acústica, com a utilização o estímulo warble, apresentado por meio dos fones TDH 39. Como critério de inclusão, foi adotada a obtenção de limiares auditivos nas frequências de 500 a $4000 \mathrm{~Hz}$ iguais ou inferiores a $15 \mathrm{~dB}$ NA, de acordo com o critério de normalidade proposto por Northern e Downs (2002).

A medida da imitância acústica foi realizada com o aparelho AT 235 da Interacoustic, a fim de averiguar a integridade do sistema tímpano-ossicular assim como da via do reflexo acústico. Como critério de inclusão, foi adotada a curva timpanométrica do tipo $\mathrm{A}$, com o pico de máxima complacência em uma faixa de 0 a -100 daPa e limiares de reflexo acústico em intensidades de 70 a 90 dB NS, segundo a classificação de Jerger (1970).

O questionário Fisher's Auditory Problems Checklist foi aplicado com os pais das crianças na faixa etária de sete a 12 anos, com o objetivo de descartar aqueles com queixas relacionadas à desordem do processamento auditivo na criança. Este questionário é composto por 25 itens, no qual os pais das crianças são solicitados a marcar com um $X$ as queixas apresentadas. A pontuação foi feita pela contagem do número de itens não marcados e multiplicados por quatro. Crianças com pontuação inferior a $72 \%$ foram excluídas da casuística (JOHNSON et al., 1997).

Como critério de inclusão no grupo experimental, os pacientes portadores de deficiência auditiva sensorial congênita, submetidos à cirurgia de IC de acordo com critérios institucionais de seleção (BEVILACQUA; MORET, 2005), que realizam 
o acompanhamento no centro, com a contínua atualização de mapeamentos e de componentes do IC. Foram descartados pacientes com diagnóstico de Desordem do Espectro da Neuropatia Auditiva e/ou hipoplasia do nervo auditivo.

\subsection{CASUÍSTICA}

Participaram deste estudo 30 usuários de IC, compondo o grupo experimental (GE), que foram implantados na idade de um a cinco anos, de ambos os sexos, com tempo de uso do dispositivo variando entre seis a 14 anos. A abordagem terapêutica informada pelos pais foi a aurioral em todos os indivíduos deste grupo.

O grupo controle (GC) foi constituído de 30 indivíduos com audição normal, pareados com a idade auditiva dos indivíduos do GE, entre quatro e 14 anos.

\subsection{METODOLOGIA}

Os procedimentos foram realizados com o processador programado no mapa mais utilizado pelo indivíduo no último retorno. No caso de indivíduos usuários de AASI, na orelha contralateral, foi solicitada a retirada do mesmo.

Para o estudo, foi realizada a pesquisa dos PEAC e a avaliação da percepção da fala, como descritos a seguir:

\subsubsection{POTENCIAIS EVOCADOS AUDITIVOS CORTICAIS}

A pesquisa dos PEAC foi realizada baseada na metodologia proposta por Ventura (2009), na qual o aparelho utilizado foi o Smart EP USB Jr da Intelligent Hearing Systems, de dois canais, o que possibilita o registro do PEA (canal A), assim como o controle da interferência dos movimentos oculares e piscada no registro (canal B). No canal $\mathrm{A}$, o eletrodo ativo posicionado em $\mathrm{Cz}$ conectado na entrada (+) do pré-amplificador e o eletrodo de referência posicionado na mastoide contralateral à orelha com o IC (M1/M2) (GUIRAUD et al., 2007) e conectado na entrada (-). No canal B, o eletrodo ativo é colocado na posição supraorbital contralateral ao lado do IC conectado na entrada (+) do pré-amplificador e o eletrodo 
de referência, na posição infraorbital desse mesmo lado, conectado na entrada (-). O eletrodo terra, posicionado em Fpz, foi conectado na posição ground (Figura 1 e 2). A determinação da amplitude da piscada delimitou o nível de rejeição utilizado em cada exame, eliminando a interferência da mesma no registro. Foram utilizados eletrodos descartáveis para ECG da marca MEDITRACE ${ }^{T M} 200$, com pasta condutiva para EEG da marca Tem $20^{\mathrm{TM}}$, que foram colocados após a limpeza da pele do indivíduo com Gel Abrasivo para ECG/EEG da marca NUPREP. O nível de impedância foi mantido entre um e três Kohms para os eletrodos.

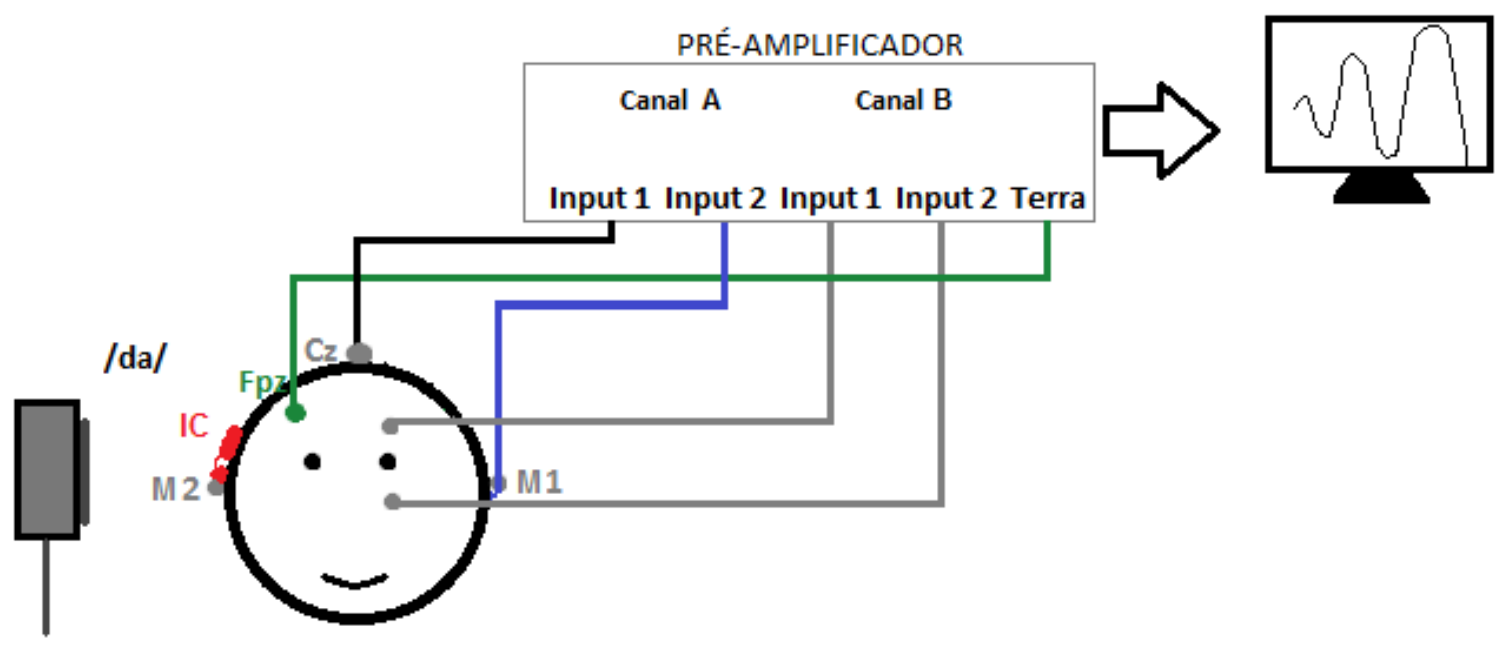

Figura 1 - Exemplo de colocação dos eletrodos para a pesquisa dos Potenciais Evocados Auditivos Corticais.

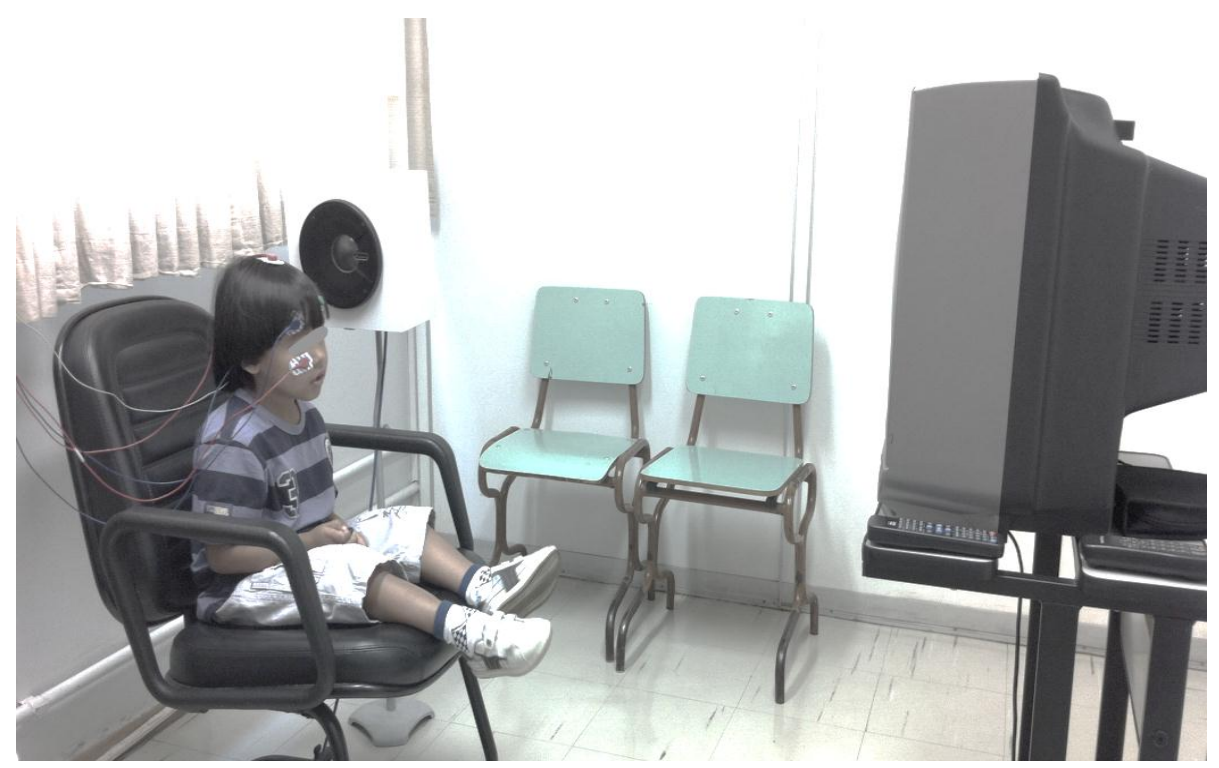

Figura 2 - Exemplo de colocação dos eletrodos para a pesquisa dos Potenciais Evocados Auditivos Corticais em um indivíduo do grupo experimental. 
O estímulo utilizado foi o de fala /da/, proposto por Banhara (2007). A amostra de fala foi construída em uma sala acusticamente tratada do Laboratório de Fonética e Psicolinguística (LAFAPE) do Instituto de Estudos da Linguagem (IEL) da Universidade Estadual de Campinas (UNICAMP). As emissões foram gravadas por meio de microfone unidirecional, diretamente na placa de computador, pelo programa livre Praat (www.praat.org), numa amostragem de $22 \mathrm{kHz}$. Foi utilizada como sinal de fala padrão a voz de um adulto jovem do sexo masculino, 22 anos de idade, com qualidade vocal fluida. A sílaba [da] foi extraída da emissão da palavra [da'da], correspondente à segunda sílaba. A partir da sílaba isolada, verificaram-se os valores de $F_{1}, F_{2}$ e $F_{3}$ em sua porção inicial e estável. Suas larguras de banda foram colhidas da região estável das frequências formantes. De posse desses valores, compilou-se um script no Praat (versão 4.2.31) e uma resíntese de cada sílaba foi realizada. A duração da sílaba [da] é de 180 ms. Os estímulos linguísticos produzidos, previamente manipulados e gravados em CD pelo LAFAPE/UNICAMP, foram digitalizados e foram inseridos na unidade $\mathrm{C}$ : do computador conectado ao software do Smart EP USB Jr da Intelligent Hearing Systems.

Como parâmetros de estimulação os estímulos de fala foram apresentados com 526 ms de intervalo interestímulo, na intensidade de $70 \mathrm{~dB}$ NA, taxa de apresentação de 1,9 estímulos por segundo. Foi utilizado filtro passa-banda de 1 a $30 \mathrm{~Hz}$, ganho de 100.000 nos dois canais, promediação de duas séries de 150 estímulos e a janela de análise da resposta de -100ms pré-estímulo e 500 ms pós-estímulo. O procedimento foi realizado em campo livre, calibrado em dB NA, com a caixa posicionada a $90^{\circ}$ azimute, a $40 \mathrm{~cm}$ de distância da orelha implantada.

A figura 3 apresenta o registro do componente $P_{1}$ dos PEAC, em duas apresentações de 150 promediações na intensidade de $70 \mathrm{~dB}$ NA e uma em $0 \mathrm{~dB}$ $\mathrm{NA}$, com o intuito de validar o registro do potencial obtido. 


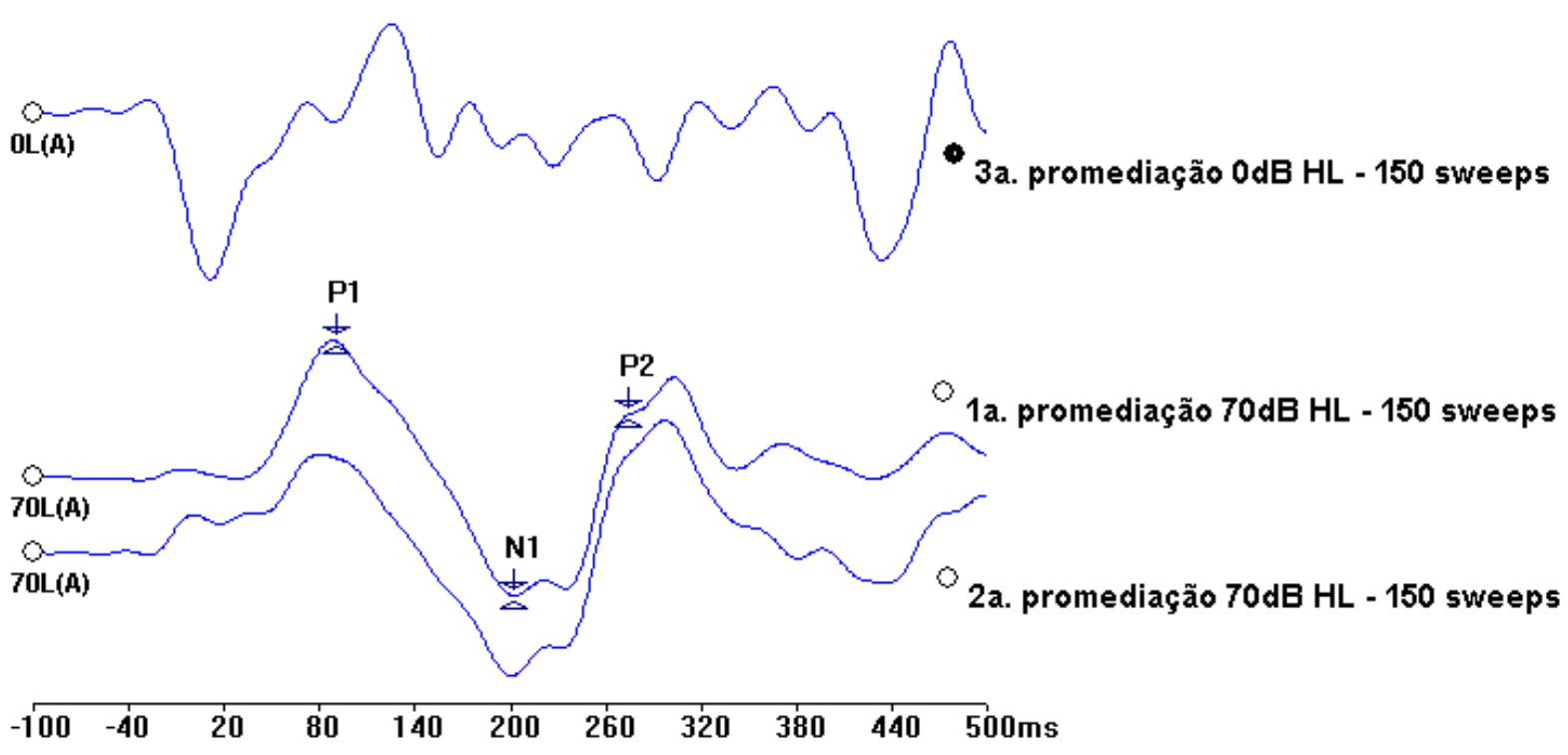

Figura 3 - Registro do complexo $\mathrm{P}_{1}-\mathrm{N}_{1}-\mathrm{P}_{2}$ dos Potenciais Evocados Auditivos Corticais em duas apresentações de 150 promediações na intensidade de 70 dB NA e uma em 0 dB NA, obtido no indivíduo 8, usuário de implante coclear Nucleus 24k, processador Freedom, estratégia $A C E$, implantado com dois anos e oito meses, com tempo de uso do IC de nove anos.

Durante a realização do exame, o indivíduo permaneceu sentado confortavelmente em uma cadeira, assistindo a um vídeo mudo, orientado a permanecer relaxado e não dormir.

Foram analisadas a amplitude e latência do componente $P_{1}$. A variável amplitude foi determinada como a diferença entre o ponto correspondente a $0,0 \mu \mathrm{V}$ (linha de base do registro) e o valor máximo positivo ou negativo, sendo marcado o ponto de máxima amplitude. Os registros foram analisados pela pesquisadora e por outra avaliadora experiente em Eletrofisiologia da audição, a fim de verificar a concordância das análises.

\subsubsection{AVALIAÇÃO DA PERCEPÇÃO DA FALA}

A avaliação da percepção da fala foi realizada no grupo experimental. O instrumento utilizado foram as listas de sentenças elaboradas por Valente (1998). Foram utilizadas as listas dois e três. Cada lista é composta por 20 sentenças, formadas por períodos simples, contendo de quatro a oito vocábulos fonológicos, com 100 palavras-chave. As sentenças foram apresentadas em campo livre a $0^{\circ}$ 
azimute, na intensidade fixa de $70 \mathrm{~dB}$ NA, com o indivíduo a um metro do altofalante. O VU meter do aparelho foi calibrado por meio de um tom puro de $1000 \mathrm{~Hz}$. Os procedimentos de percepção da fala foram realizados em cabina acústica de $2 \mathrm{~m}$ $x 2 \mathrm{~m}$. Foi solicitado que o indivíduo repetisse a sentença e o resultado foi baseado no número de palavras-chave identificadas e repetidas corretamente. A análise do percentual de acerto foi realizada por meio do cálculo, no qual o número de acerto das palavras foi multiplicado por cem.

$\mathrm{Na}$ realização da avaliação da percepção de fala, foi utilizado o audiômetro de dois canais "Midimate 622 - Madsen Eletronics", conectado a um amplificador em campo livre e duas caixas acústicas. As sentenças foram apresentadas utilizando um reprodutor de CD "Teac PD-P30 - Compact disc digital audio", acoplado a um canal do audiômetro, apresentados ipsilateralmente em campo livre.

Para anotação dos resultados da avaliação da percepção de fala, foram utilizados formulários impressos (ANEXOS C e D).

\subsection{ANÁLISE ESTATÍSTICA}

Foi utilizado 0 teste de normalidade de Kolmogorov-Smirnov (CHAKRAVARTI et al., 1967), demonstrando a possibilidade de utilização de testes paramétricos. Para a comparação dos resultados entre os grupos controle e experimental, foram utilizados os Teste T e o Teste de Mann-Whitney. Foi adotado como nível de significância $p \leq 0,05$. 


\section{Resultados}



5 REULTADOS

Os valores de latência e amplitude do componente $P_{1}$ dos PEAC e o desempenho da percepção de fala para cada indivíduo encontram-se no Apêndice (APÊNDICE A).

A caracterização do GE quanto ao tempo de privação sensorial, uso do IC, estratégia de processamento do sinal acústico, idade de ativação e idade cronológica encontra-se na Tabela 1.

Tabela 1 - Caracterização do grupo experimental quanto ao tipo de implante coclear, processador de fala, estratégia de processamento do sinal acústico, idade de ativação do dispositivo, idade cronológica e tempo de uso em anos.

\begin{tabular}{|c|c|c|c|c|c|c|}
\hline ID & Implante Coclear & Processador & Estratégia & $\begin{array}{c}\text { Idade } \\
\text { Ativação }\end{array}$ & $\begin{array}{c}\text { Idade } \\
\text { Cronológica }\end{array}$ & $\begin{array}{l}\text { Tempo } \\
\text { de Uso }\end{array}$ \\
\hline 1 & Nucleus 24k & Freedom & $A C E$ & $2 a 5 m$ & 12 & 9 \\
\hline 2 & Nucleus 24k & Freedom & $A C E$ & $3 a 10 m$ & 17 & 13 \\
\hline 3 & Nucleus 24k & Freedom & $A C E$ & $3 a 3 m$ & 16 & 13 \\
\hline 4 & Nucleus 24k & Freedom & ACE & $2 \mathrm{a} 7 \mathrm{~m}$ & 12 & 9 \\
\hline 5 & Nucleus 24k & Freedom & ACE & $1 \mathrm{a} 4 \mathrm{~m}$ & 8 & 6 \\
\hline 6 & Nucleus 24k & Freedom & ACE & $3 a 11 m$ & 10 & 7 \\
\hline 7 & Nucleus 24k & Freedom & $A C E$ & $3 a 4 m$ & 17 & 14 \\
\hline 8 & Nucleus 24k & Freedom & ACE & $2 a 8 m$ & 12 & 9 \\
\hline 9 & Nucleus 24k & Freedom & ACE & $3 a 2 m$ & 10 & 7 \\
\hline 10 & Nucleus 24k & Freedom & ACE & $1 \mathrm{a} 10 \mathrm{~m}$ & 11 & 7 \\
\hline 11 & Nucleus 24k & Freedom & $A C E$ & $1 \mathrm{a} 2 \mathrm{~m}$ & 10 & 9 \\
\hline 12 & Nucleus 24k & Freedom & ACE & $3 a 2 m$ & 10 & 7 \\
\hline 13 & Nucleus 24k & Freedom & $A C E$ & $2 a 6 m$ & 8 & 6 \\
\hline 14 & Nucleus 24k & Freedom & ACE & $2 a 2 m$ & 9 & 7 \\
\hline 15 & Nucleus 24k & Freedom & ACE & $3 a 4 m$ & 10 & 7 \\
\hline 16 & Nucleus $24 k$ & Freedom & $A C E$ & $3 a 7 m$ & 10 & 6 \\
\hline 17 & Nucleus 24k & Freedom & ACE & $2 a 4 m$ & 10 & 8 \\
\hline 18 & Nucleus 24k & Freedom & ACE & $2 a 7 m$ & 9 & 7 \\
\hline 19 & Nucleus 24k & Freedom & ACE & $2 a 7 m$ & 12 & 9 \\
\hline 20 & Nucleus 24k & Freedom & ACE & $3 a 9 m$ & 17 & 13 \\
\hline 21 & Nucleus 24k & Freedom & $A C E$ & $2 a$ & 8 & 6 \\
\hline 22 & Nucleus 24k & Freedom & ACE & $3 a 11 m$ & 10 & 6 \\
\hline 23 & Nucleus 24k & Freedom & ACE & $3 a 5 m$ & 10 & 6 \\
\hline 24 & Nucleus 24k & Freedom & ACE & $2 \mathrm{a} 10 \mathrm{~m}$ & 9 & 7 \\
\hline 25 & MedEl C40+ & Tempo + & $\mathrm{CIS}+$ & $3 a 1 m$ & 15 & 12 \\
\hline 26 & MedEl C40+ & Tempo + & $\mathrm{ClS}+$ & $1 \mathrm{a} 11 \mathrm{~m}$ & 14 & 12 \\
\hline 27 & MedEl C40+ & Tempo + & CIS+ & $3 a 1 m$ & 15 & 12 \\
\hline 28 & MedEl C40+ & Tempo + & CIS+ & $2 \mathrm{a} 10 \mathrm{~m}$ & 15 & 11 \\
\hline
\end{tabular}




\begin{tabular}{ccccccc}
\hline \hline 29 & MedEl C40+ & Tempo + & ClS + & $4 \mathrm{a} 4 \mathrm{~m}$ & 16 & 12 \\
30 & MedEl C40+ & Tempo + & ClS + & $2 \mathrm{a} 10 \mathrm{~m}$ & 9 & 6 \\
\hline
\end{tabular}

Legenda: ID - identificação; a - anos; $m$ - meses.

\subsection{MORFOLOGIA DOS REGISTROS}

No GE, o componente $\mathrm{P}_{1}$ foi registrado em todos os indivíduos avaliados. A figura 2 exemplifica o registro obtido em um indivíduo do GE, no qual foi registrado o complexo $\mathrm{P}_{1}-\mathrm{N}_{1}-\mathrm{P}_{2}$.

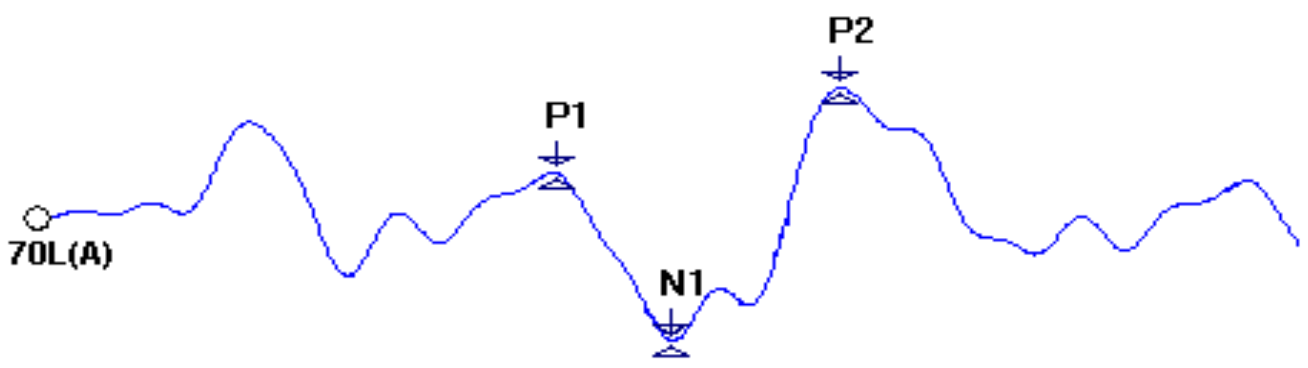

$\begin{array}{lllllllllll}-100 & -40 & 20 & 80 & 140 & 200 & 260 & 320 & 380 & 440 & 500 m s\end{array}$

Figura 4 - Registro dos Potenciais Evocados Auditivos Corticais do indivíduo sete do grupo experimental, com idade auditiva de 14 anos, implantado com 3 anos e 4 meses, usuário do IC Nucleus 24k, processador Freedom, estratégia ACE, com oito anos de uso.

\subsection{ANÁLISE INFERENCIAL}

A tabela 2 apresenta a análise descritiva do tempo de uso, idade na cirurgia, percepção de fala, latência (ms) e amplitude $(\mu \mathrm{V})$ do componente $P_{1}$, dos indivíduos dos GE e GC.

Tabela 2 - Análise descritiva do tempo de uso, idade na cirurgia, percepção de fala, latência (ms) e amplitude $(\mu \mathrm{V})$ do componente $P_{1}$ para os grupos experimental e controle.

\begin{tabular}{|c|c|c|c|c|c|c|c|}
\hline & \multirow{2}{*}{$\begin{array}{l}\text { Tempo } \\
\text { de uso }\end{array}$} & \multirow{2}{*}{$\begin{array}{c}\text { Idade na } \\
\text { Cirurgia }\end{array}$} & \multirow{2}{*}{$\begin{array}{c}\text { Percepção } \\
\text { de fala }\end{array}$} & \multicolumn{2}{|c|}{ Latência $\mathbf{P}_{1}$} & \multicolumn{2}{|c|}{ Amplitude $\mathbf{P}_{1}$} \\
\hline & & & & GE & GC & GE & GC \\
\hline Média & 8 a $7 \mathrm{~m}$ & 2 a $4 \mathrm{~m}$ & $70 \%$ & 131,87 & 88,40 & 2,42 & 3,69 \\
\hline DP & 2 a $6 \mathrm{~m}$ & $7 \mathrm{~m}$ & $17 \%$ & 34,46 & 17,38 & 1,46 & 1,58 \\
\hline Mínimo & $6 a$ & $1 \mathrm{a} 2 \mathrm{~m}$ & $37 \%$ & 67,0 & 57,0 & 0,26 & 1,46 \\
\hline Máximo & $14 a$ & 4 a $4 \mathrm{~m}$ & $97 \%$ & 202,0 & 142,0 & 5,92 & 8,59 \\
\hline Mediana & 7 a $5 \mathrm{~m}$ & 2 a $10 \mathrm{~m}$ & $73 \%$ & 134,0 & 85,0 & 2,01 & 3,23 \\
\hline
\end{tabular}

Legenda: GE - Grupo Experimental; GC - Grupo Controle; a - anos; m - meses. 
Os Gráficos 1 e 2 apresentam o comportamento da latência e amplitude do componente $\mathrm{P}_{1}$ de acordo com as médias das idades, para os grupos controle e experimental.

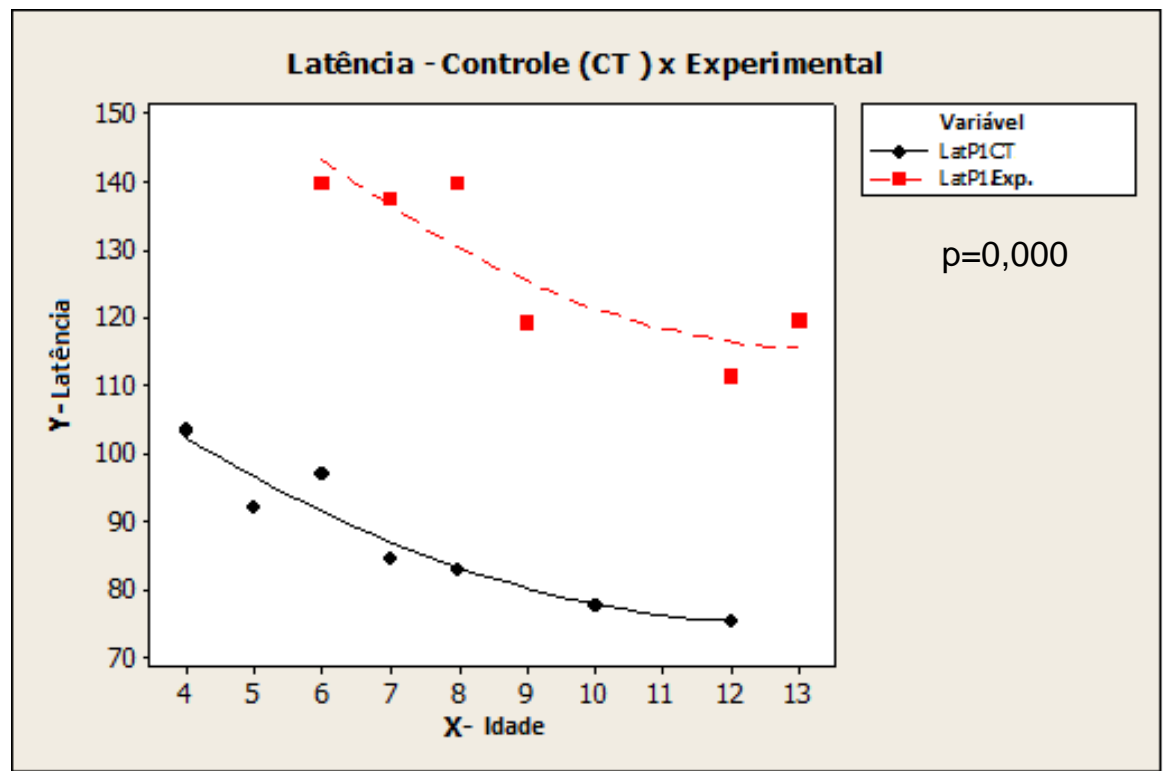

Gráfico 1 - Comportamento da latência (ms) do componente $P_{1}$, de acordo com as idades, para os grupos controle e experimental.

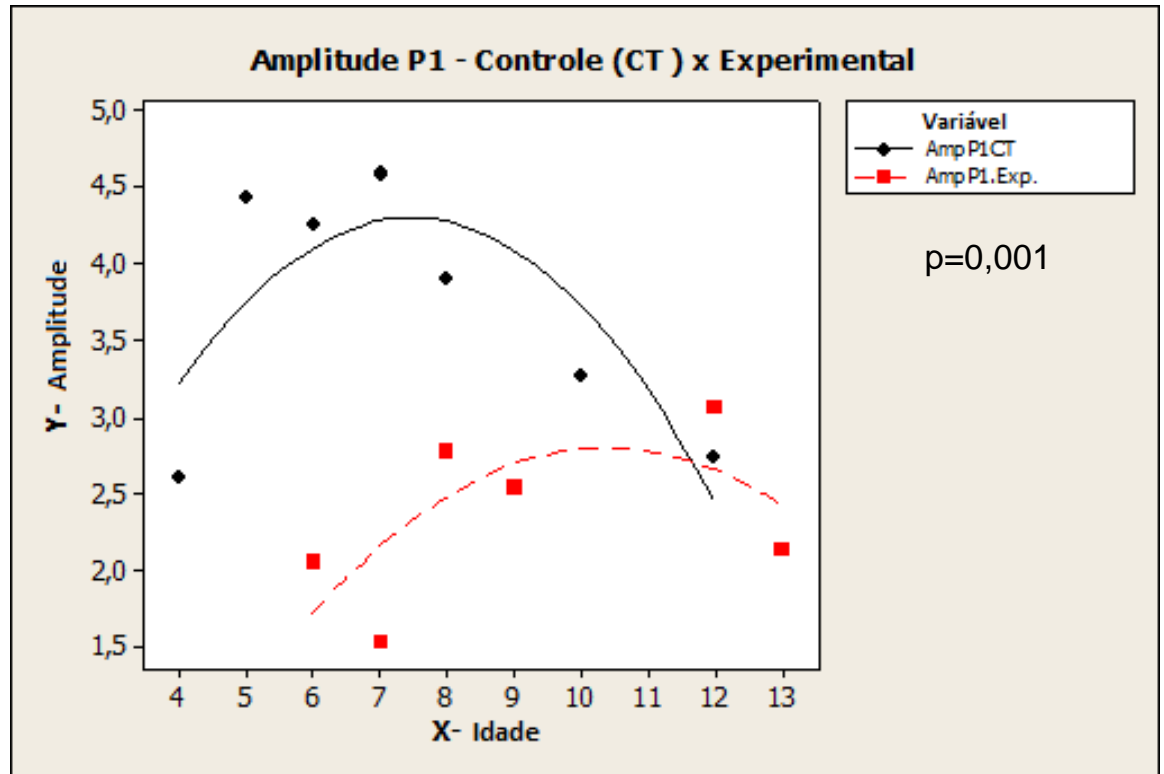

Gráfico 2 - Comportamento da amplitude $(\mu \mathrm{V})$ do componente $P_{1}$, de acordo com as idades, para os grupos controle e experimental. 
As análises da latência e amplitude do componente $P_{1}$, para $\circ \mathrm{GE}$, considerando dois grupos definidos, de acordo com a idade na cirurgia: $\leq 3,5$ anos e $>3,5$ anos, encontram-se nos gráficos 3 e 4, respectivamente.

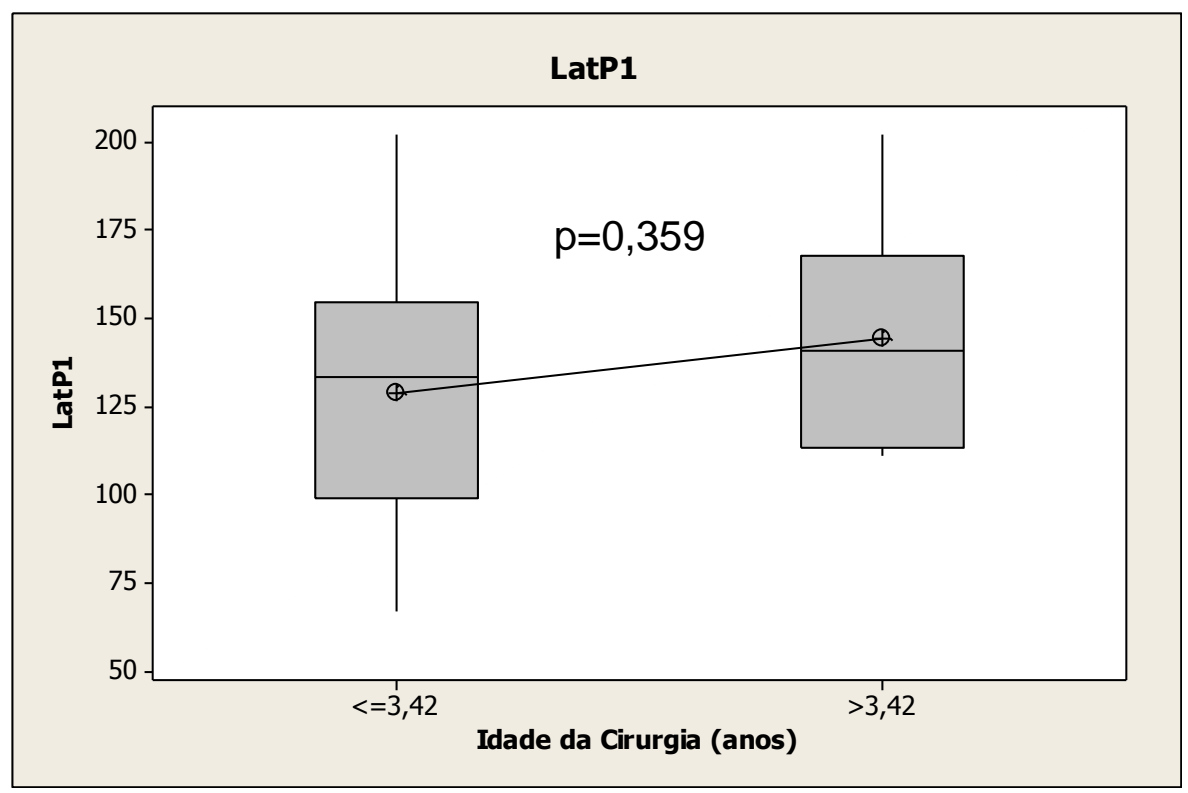

Gráfico 3 - Análise estatística da latência $(\mathrm{ms})$ do componente $\mathrm{P}_{1}$ considerando dois grupos, de acordo com a idade na cirurgia ( $\leq 3,5$ anos $\mathrm{e}>3,5$ anos).

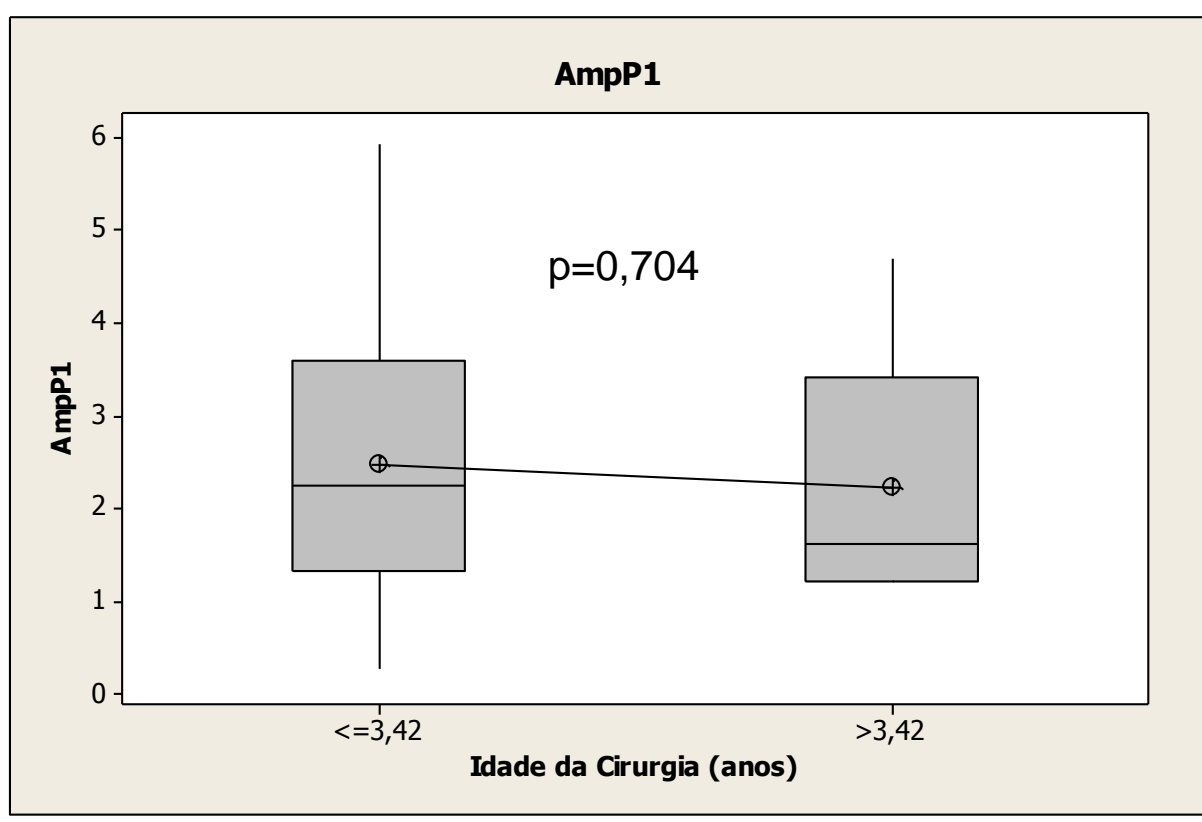

Gráfico 4 - Análise estatística da amplitude $(\mu \mathrm{V})$ do componente $P_{1}$ considerando dois grupos, de acordo com a idade na cirurgia $(\leq 3,5$ anos $e>$ 3,5 anos). 
Os gráficos 5 e 6 apresentam, respectivamente, a análise da latência e amplitude do componente $\mathrm{P}_{1}$ do $\mathrm{GE}$, considerando dois grupos, de acordo com o tempo de uso do IC.

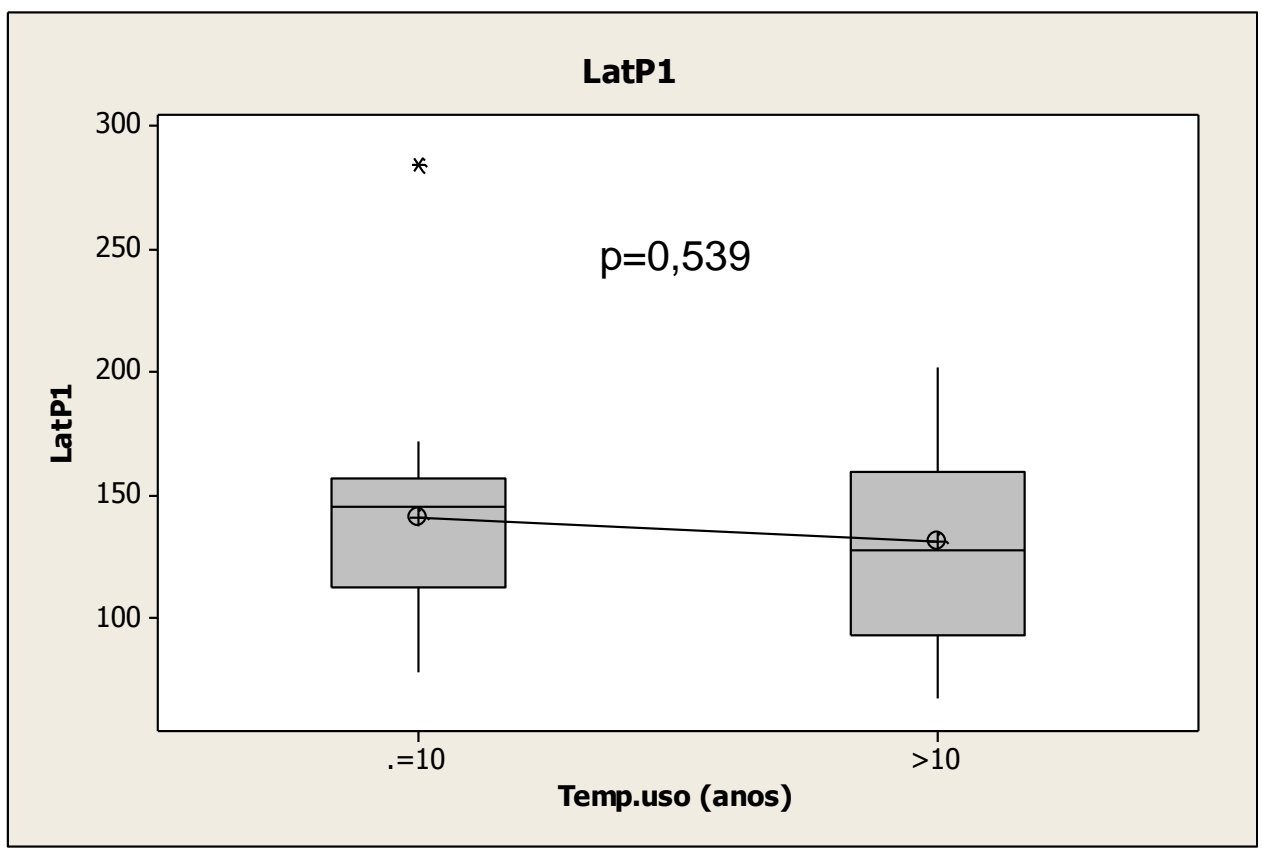

Gráfico 5 - Análise estatística da latência $(\mathrm{ms})$ do componente $\mathrm{P}_{1}$ considerando dois grupos, de acordo com o tempo de uso do dispositivo ( $\leq 10$ anos e $>10$ anos).

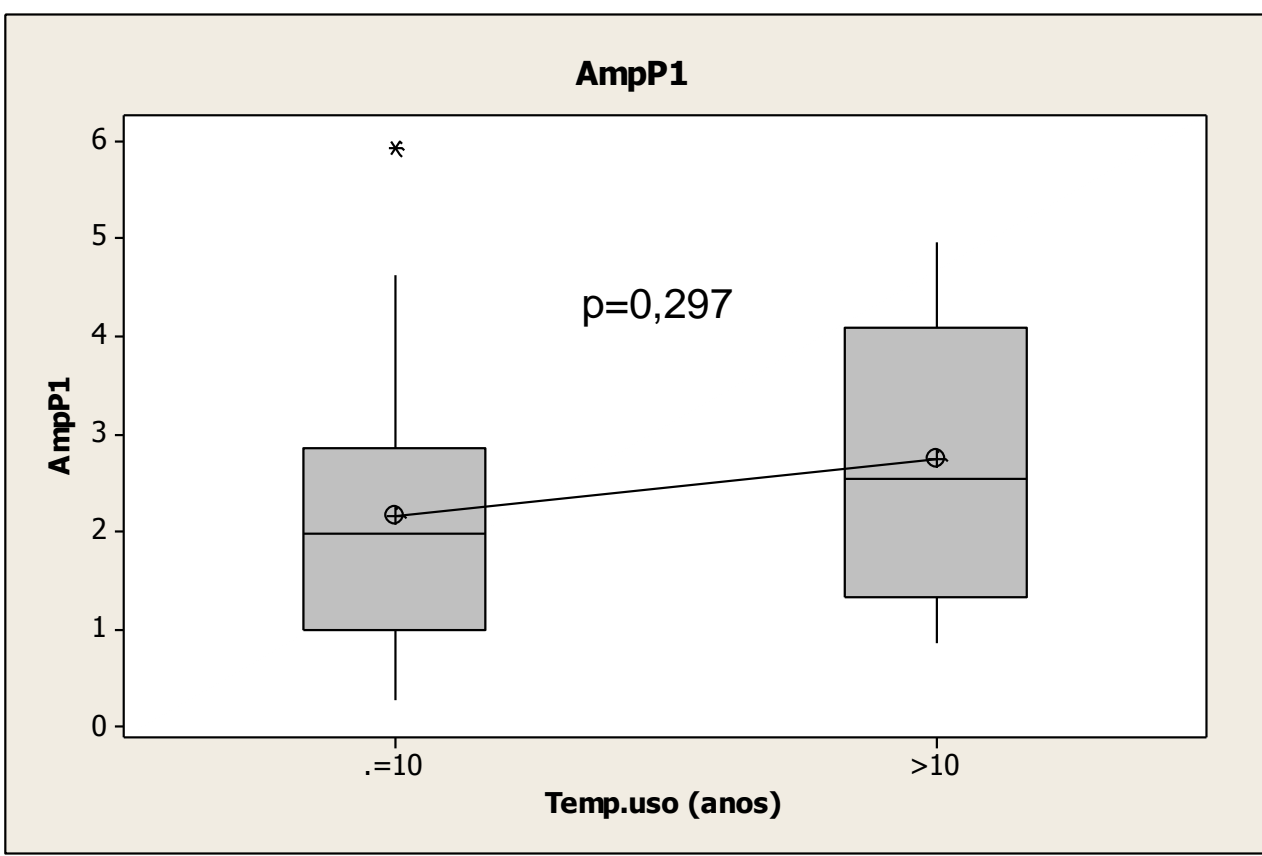

Gráfico 6 - Análise estatística da amplitude $(\mu \mathrm{V})$ do componente $P_{1}$ considerando dois grupos, de acordo com o tempo de uso do dispositivo ( $\leq 10$ anos e $>10$ anos). 
A análise da latência e amplitude do componente $P_{1}$ do $G E$, considerando dois grupos, de acordo com o desempenho no teste de percepção da fala com sentenças, encontra-se nos gráficos 7 e 8 .

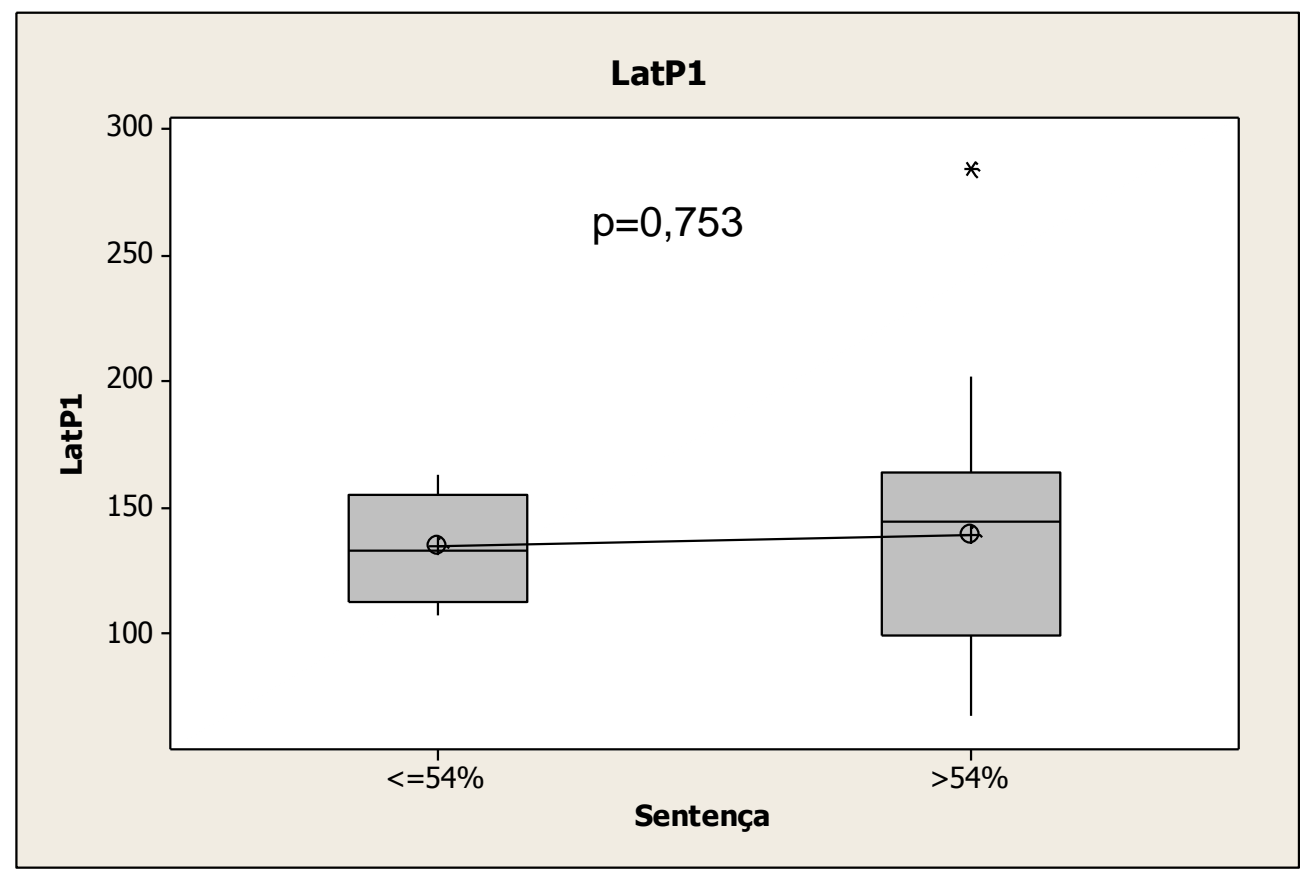

Gráfico 7 - Análise estatística da latência $(\mathrm{ms})$ do componente $P_{1}$ em dois grupos, de acordo com o desempenho no teste de percepção da fala com sentenças.

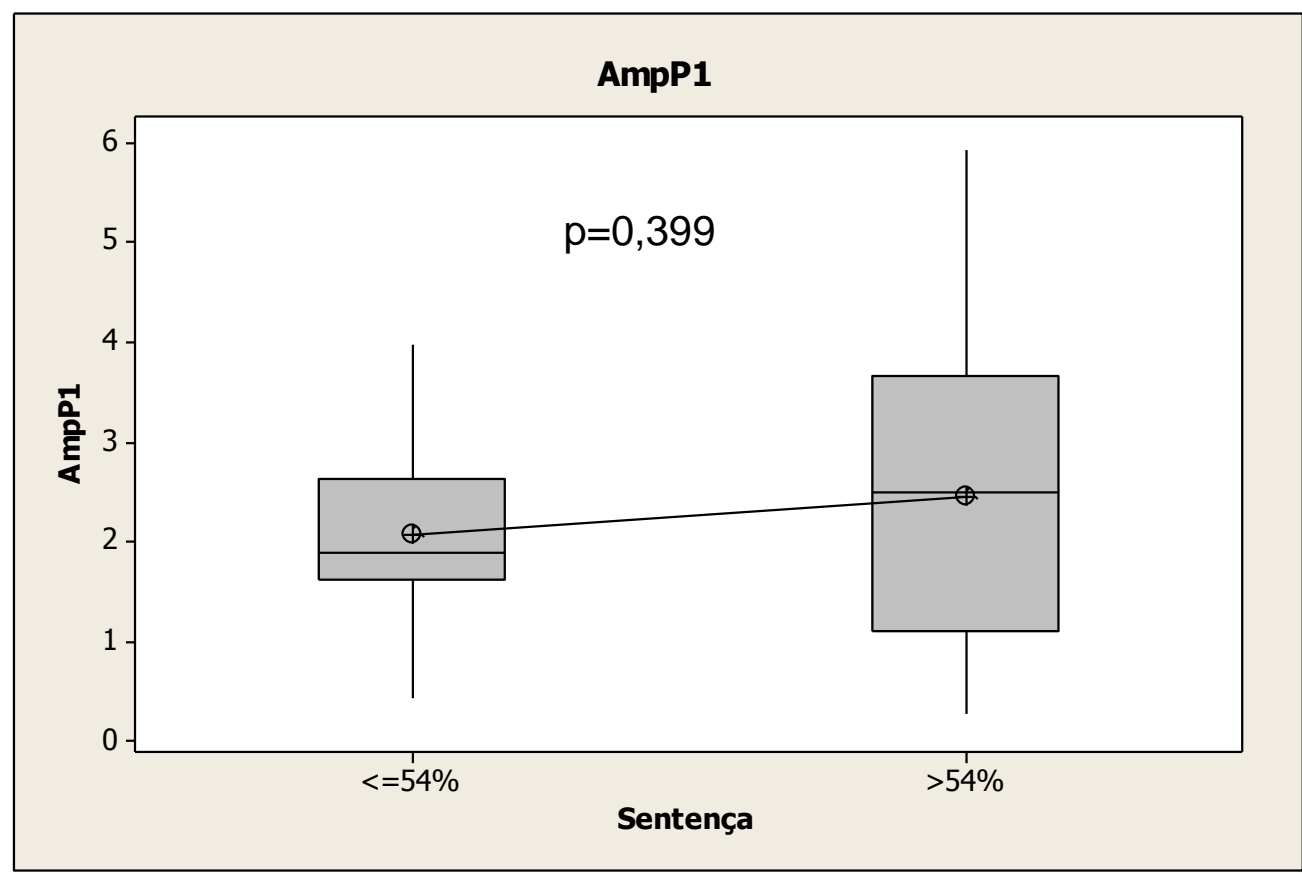

Gráfico 8 - Análise estatística da amplitude $(\mu \mathrm{V})$ do componente $P_{1}$ em dois grupos, de acordo com o desempenho no teste de percepção de fala com sentenças. 
A análise estatística do desempenho do GE, nos testes de percepção da fala, com sentenças, considerando dois grupos, de acordo com o tempo de uso do IC encontra-se no gráfico 9.

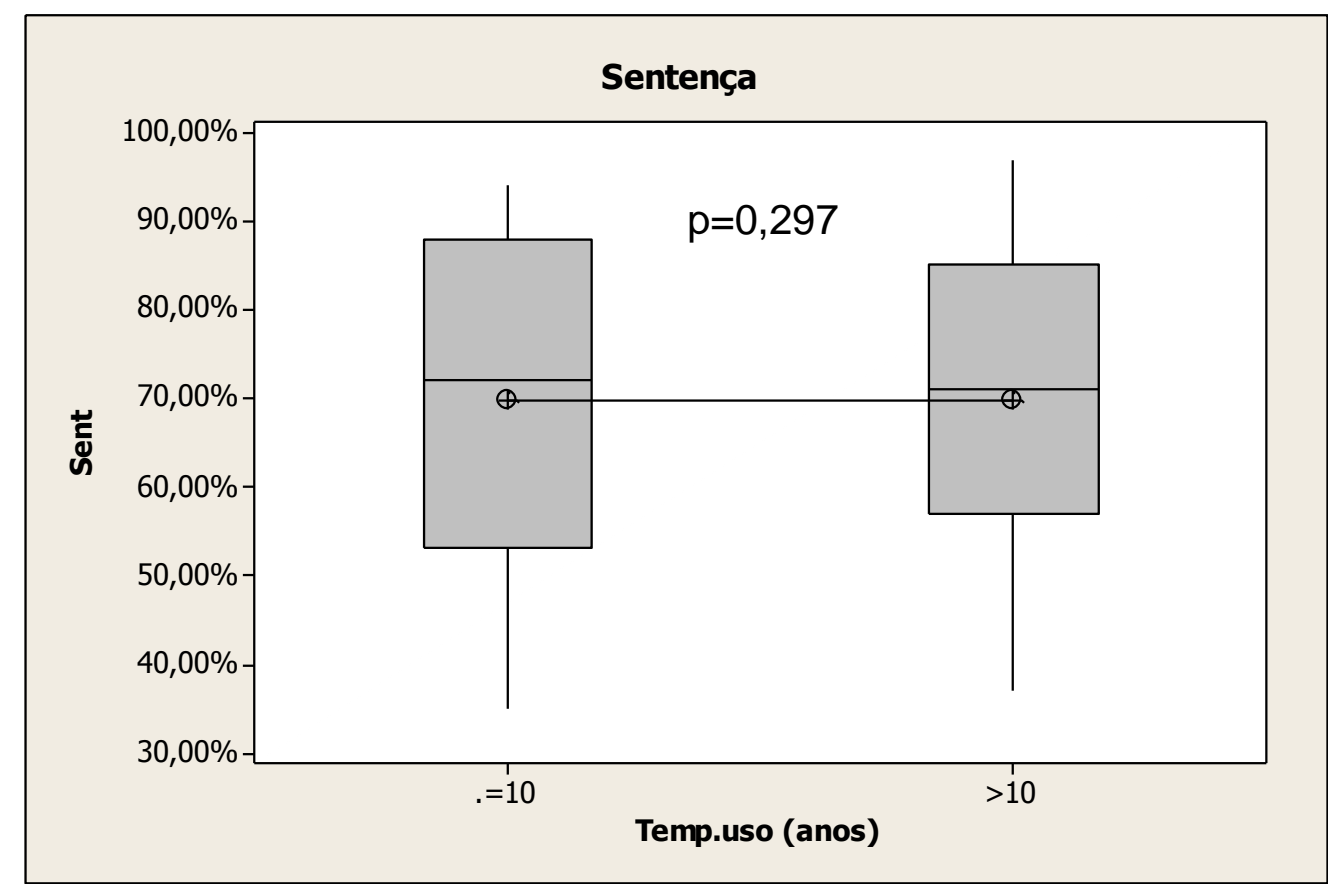

Gráfico 9 - A análise estatística do desempenho, nos testes de percepção da fala, com sentenças, considerando dois grupos, de acordo com o tempo de uso do IC ( $\leq 10$ anos e $>10$ anos). 


6 Discussão 




\section{DISCUSSÃO}

O sistema nervoso auditivo apresenta mudanças fisiológicas que refletem o processo maturacional das vias auditivas frente à estimulação acústica, que podem ser observadas por meio do registro dos PEAC. Caracteristicamente, no decorrer deste processo, observa-se diminuição da latência e aumento da amplitude, devido à mielinização e definição das sinapses neurais. O processo de maturação é estímulo-dependente. Sendo assim, durante o período de privação sensorial decorrente da perda auditiva, ocorre a reorganização das estruturas neurais, ou seja, estruturas primariamente auditivas são apropriadas por outra função sensorial, como, por exemplo, a visão. Com o restabelecimento da audição, por meio do IC, ocorre o redirecionamento das estruturas neurais para sua função primária parcial ou totalmente. Isto porque, a plasticidade neuronal ocorre ao longo da vida do indivíduo; no entanto, com o passar dos anos, há uma redução nesta capacidade proporcionando um redirecionamento não efetivo.

Estudos realizados com indivíduos com DA congênitos, usuários de IC, demonstraram que o processo maturacional do sistema auditivo central inicia-se no momento em que a energia elétrica é oferecida pelo dispositivo diretamente ao nervo auditivo, com o registro do componente $\mathrm{P}_{1}$ imediatamente após a ativação (SHARMA et al., 2002; KELLY et al., 2005; GILLEY et al., 2008; SHARMA et al., 2009; KRAL; SHARMA, 2011; CASTAÑEDA-VILLA et al., 2012; ). Estes achados enfatizam que a maturação de parte do córtex auditivo associado à geração do PEAC, mais especificamente o componente $P_{1}$, não acompanha um curso autônomo na ausência da entrada auditiva (SINGH et al., 2004), mas com o restabelecimento da audição, a maturação evolui de acordo com o tempo de uso do IC. Nossos resultados demonstraram que a latência do componente $P_{1}$ diminui com a idade seguindo um curso semelhante ao dos indivíduos ouvintes; no entanto, com valores de latência aumentados (gráfico 1), o que corrobora com os estudos desenvolvidos por Ponton et al. (1996), Singh et al. (2004), Ponton e Eggermont (2001). Da mesma forma, a amplitude do componente $P_{1}$ mostrou-se menor no grupo experimental (gráfico 2), o que demonstra que a maturação ocorre aquém do esperado, porém segue o mesmo curso no qual a amplitude chega a um valor máximo, com posterior declínio. Neste sentido, é preciso considerar que a criança ouvinte está 24 horas por dia em contato com o ambiente auditivo, ao contrário da 
criança com DA que desliga o seu dispositivo em diversas situações, como por exemplo, ao dormir ou em atividades de lazer em que o uso do IC não seja possível. Assim, é possível considerar que o padrão maturacional do sistema auditivo que é estímulo-dependente como discutido anteriormente, sofre o impacto adicional destes pequenos períodos de privação sensorial, o que pode justificar a diferença na latência e amplitude do componente $P_{1}$.

Evidências científicas demonstraram que o padrão de maturação é dependente do tempo de privação sensorial, aspecto que incide nos resultados de desenvolvimento do córtex auditivo (PONTON et al., 1996; PONTON; EGGERMONT, 2001; SHARMA et al., 2002; SHARMA et al., 2004; KELLY et al., 2005; SHARMA et al., 2005; WUNDERLICHI et al., 2006; GILLEY et al., 2008; SHARMA et al., 2009; KRAL; SHARMA, 2011). De acordo com os achados de Sharma et al. (2005), o período sensível para indicação do IC que possibilita o desenvolvimento biológico, cognitivo e de linguagem oral como de uma criança ouvinte é até a idade de três anos e cinco meses, com limitação a partir de sete anos. Na idade intermediária (entre os 3,5 anos e 7 anos), os autores constataram que os resultados podem ser muito variáveis, mesmo seguindo os critérios multifatoriais de indicação.

Neste estudo, as crianças foram submetidas à cirurgia nas idades entre um ano e um mês a quatro anos e quatro meses (tabela 2), sendo que 24 crianças encontravam-se no período considerado sensível (1,1 a 3,5 anos) e seis crianças na idade intermediária (3,5 a 4,4 anos), como demonstrado na tabela 1. Desta forma, considerou-se a possibilidade da variabilidade na idade do GE ter influenciado nos resultados obtidos; contudo, não foi observada diferença estatisticamente significante na latência média $(p=0,359)$ e amplitude média $(p=0,704)$ entre o grupo formado por crianças que foram submetidas à cirurgia em idade inferior a três anos e cinco meses e aquele de crianças com idade acima (gráficos 3 e 4).

Neste contexto, foi analisada a influência do tempo de uso do IC nas características do componente $P_{1}$. Como observado nos gráficos 5 e 6 , ocorre uma redução da latência $(p=0539)$ e o aumento da amplitude $(p=0,297)$ do componente $P_{1}$, mas não foi encontrada diferença significante entre os grupos com menos e mais de 10 anos do uso do dispositivo eletrônico.

Ao analisar o desempenho na percepção da fala e as características do componente $\mathrm{P}_{1}$, pela pontuação comportamental, foi considerado como desempenho 
"bom" o escore $>54 \%$, e "ruim" $\leq 54 \%$, e em posterior análise da média de latência do $P_{1}(p=0753)$ e da amplitude $(p=0,399)$ em ambos grupos, não foi encontrada diferença estatisticamente significante (gráficos 7 e 8), ou seja, não houve uma associação entre o desempenho na percepção da fala e o potencial cortical $P_{1}$. Segundo Ponton \& Eggermont (2001), a alteração dos PEAC de crianças usuárias de IC é reflexo das alterações do processo cortical de sensação e percepção correlacionado com o desenvolvimento de processos corticais de mais alta complexidade, como a produção e percepção da linguagem oral. Contudo, conforme descrito por Singh et al. (2004), a maturação das vias corticais que dão origem a $P_{1}$ não parece estar relacionada à proficiência na linguagem receptiva e expressiva, uma vez que nenhum padrão de maturação foi observado quando comparada à latência de $\mathrm{P}_{1}$ com escore comportamental, o que está condizente com o obtido no presente estudo. Ao considerar o desempenho na percepção de fala, de acordo com o tempo de uso do IC, não foi encontrada diferença nos escores médios entre as crianças com menos e mais de 10 anos de uso do IC (gráfico 9).

De acordo com Davidson et al., (2011), responder corretamente ao teste de percepção da fala requer não somente a percepção auditiva mas também conhecimento lexical dos itens dos estímulos e articulação da resposta falada. Assim, as mudanças no desempenho na percepção de fala em crianças utilizando o IC são acompanhadas por fatores maturacionais e de intervenção, sendo difícil determinar a contribuição única da habilidade de ouvir.

Estudos têm investigado a relação entre os resultados de linguagem e possíveis preditores dos resultados com o IC, que podem ser divididos em três categorias: fatores auditivos relacionados à reabilitação auditiva, fatores relacionados à criança que são inerentes à mesma, como desenvolvimento cognitivo e fatores ambientais.

Geers (2002), Stuchi et al. (2007), Moret et al. (2007), Flexer (2011), Davidson et al. (2011) e Tanamati (2012) relataram que o desenvolvimento da linguagem é dependente de outros aspectos, tais como a tecnologia do IC, envolvimento dos pais no processo de reabilitação, uso da comunicação oral, tempo de exposição diária ao ambiente sonoro, aspectos psicossociais, a estratégia de codificação dos sons da fala e a permeabilidade da família. 
Ao analisar tais aspectos, sugeriu-se a realização de dois casos controles, que revelaram a influência dos aspectos extrínsecos ao indivíduo nos benefícios obtidos com o IC:

Caso 1: criança com diagnóstico de perda auditiva de grau severo, de etiologia idiopática, com desenvolvimento cognitivo adequado, idade na cirurgia de quatro anos e quatro meses, com tempo de uso do IC de oito anos, IC na orelha direita, Nucleus 24k, processador Nucleus 5, estratégia de processamento do sinal ACE. Nos atendimentos de acompanhamento constatou-se que a família é participativa no processo terapêutico, reabilitação no método auri-oral, com uso efetivo do IC e frequenta escola regular. A pesquisa dos PEAC apontou as seguintes características do componente $P_{1}$ : valores de latência em $113 \mathrm{~ms}$ e amplitude em $0,93 \mu \mathrm{V}$ semelhante à normalidade, com resultado do teste de percepção da fala em $66 \%$.

Caso 2: criança com diagnóstico de perda auditiva sensorial de grau severo de etiologia idiopática realizou a cirurgia com idade de dois anos e dez meses, faz uso do IC Nucleus $24 k$, processador Freedom, estratégia de processamento do sinal $A C E$, com tempo de uso do dispositivo eletrônico de sete anos, sem alterações no desenvolvimento cognitivo. Devido à região em que vive, demonstrou dificuldade de acesso à terapia de reabilitação apresentando um número relativamente alto de faltas. A pesquisa dos PEAC apontou as seguintes caraterísticas do componente $\mathrm{P}_{1}$ : valores de latência em $133 \mathrm{~ms}$ e amplitude em $2,25 \mu \mathrm{V}$, o teste de percepção da fala foi de $50 \%$.

Os casos apresentados demonstram que o IC possibilita a restauração da função de ouvir, pois garante a estimulação elétrica do sistema auditivo e, consequentemente, a detecção do som. No entanto, a aquisição das habilidades auditivas depende da qualidade da estimulação, ou seja, o IC, por si só, não permite o desenvolvimento da função auditiva que envolve habilidades no processamento auditivo do som que são pré-requisitos para a aquisição e desenvolvimento da linguagem oral.

A realização da cirurgia em idade ideal é fundamental para que ocorra a reorganização do sistema auditivo e, consequentemente, existam as condições intrínsecas à criança para o desenvolvimento das habilidades comportamentais. Contudo, aspectos como participação familiar no processo de reabilitação auditiva e adequada abordagem terapêutica influenciam significativamente nos benefícios 
obtidos com o IC (DAVIDSON et al.,2011). Sugere-se a realização de novos estudos que visem o acompanhamento do processo terapêutico de indivíduos com DA usuários de IC, por meio de instrumentos como a rede de telessaúde, em que abordem as diversificadas regiões do Brasil, país de extensa dimensão territorial. 


7 Conclusões 




\section{CONCLUSÕES}

A presença do componente $P_{1}$ em indivíduos usuários de IC demonstra que o IC restaura a capacidade de ouvir. O padrão maturacional do potencial cortical segue o curso semelhante ao da criança ouvinte, porém com um atraso na latência e diminuição da amplitude. Após longo período de uso do IC, o componente $\mathrm{P}_{1}$ não é um preditor único do desempenho na percepção de fala. 


$\underline{\text { Referências }}$ 




\section{REFERÊNCIAS}

AGOSTINHO-PESSE, R. S. Potencial evocado auditivo de longa latência para o estímulo de fala apresentado com diferentes transdutores em crianças normais. 2011. Dissertação (Mestrado em Fonoaudiologia) - Faculdade de Odontologia de Bauru, Universidade de São Paulo, Bauru, 2011.

ANGELO, T. C. S.; BEVILACQUA, M. C.; MORET, A. L. M. Percepção da fala em deficientes auditivos pré-linguais usuários de implante coclear. Pró-Fono Revista de Atualização Científica, v. 22, n. 3, p. 275-280, 2010.

BANHARA, M. R. Potenciais auditivos de longa latência: $\mathbf{N}_{1}, \mathbf{P}_{2}, \mathbf{N}_{\mathbf{2}}, \mathbf{e} \mathbf{P}_{\mathbf{3 0 0}}$, evocados por estímulo de fala em usuários de implante coclear. 2007. 79 p. Dissertação (Mestrado em Ciências) - Faculdade de Medicina da Universidade de São Paulo, Universidade de São Paulo, São Paulo, 2007.

BAUER, P. W. et al. Central auditory development in children with bilateral cochlear implants. Archives of Otolaryngology-Head \& Neck Surgery, v. 132, n. 10, Oct 2006.

BEITER, A. L.; SHALLOP, J. K. Cochlear implants: past, present and future. In: Estabrooks, W. Cochlear implants for kids. Washington: Alexander Graham Bell Association for the Deaf, p. 3-29, 1998.

BEVILACQUA, M. C.; MORET, A. L. M. Reabilitação e implante coclear. In: LOPES FILHO, O. Tratado de fonoaudiologia. Ribeirão Preto: Tecmedd, cap. 23, p. 423-436, 2005.

BEYNON, A. J.; SNIK, A. F. M.; VAN DEN BROEK, P. Evaluation of cochlear implant benefit with auditory cortical evoked potentials. International Journal of Audiology, v. 41, n. 7, p. 429-435, Oct 2002.

BONALDI, L. V. Sistema Auditivo Periférico. In: BEVILACQUA, M. C.; MARTINEZ, M. A. N.; BALEN, S. A.; PUPO, A. C.; REIS, A. C. M. B.; FROTA, S. Tratado de Audiologia. São Paulo: Ed. Santos, p. 3-27, 2011.

BOONS, T. et al. Predictors of Spoken Language Development Following Pediatric Cochlear Implantation. Ear and Hearing, v. 33, n. 5, Sep-Oct 2012.

BROWN, C. J. et al. The electrically evoked auditory change complex: preliminary results from nucleus cochlear implant users. Ear and Hearing, v. 29, n. 5, p. 704717, 2008. 
CASTAÑEDA-VILLA, N. et al. Quantification of LLAEP interhemispheric symmetry by the intraclass correlation coefficient as a measure of cortical reorganization after cochlear implantation. International Journal of Pediatric Otorhinolaryngology, v. xxx, n.xxx, p. xxx-xxx, Aug 2012.

CHAKRAVARTI, I. M.; LAHA, R. G.; ROY, J. Handbook of Methods of Applied Statistics. Ed. J. Wiley and Sons, v. 1, p. 392-394, 1967.

CONE-WESSON, B.; WUNDERLICH, J. Auditory evoked potentials from the cortex: audiology applications. Curr Opin Otolaryngol Head Neck Surg, v. 11, n. 5, p.372377, Oct 2003.

CONWAY, C. M.; PISONI, D. B.; ANAYA, E. M.; KARPICKE, J.; HENNING, S. C. Implicit sequence learning on deaf children with cochlear implants. Developmental Science, v. 14, n. 1, p. 69-89, 2011.

COSTA FILHO, O. A. Implantes cocleares multicais no tratamento da surdez em adultos. 1998. Tese (Doutorado) - Faculdade de Odontologia de Bauru, Universidade de São Paulo, Bauru, 2008.

COX, R. M. Evidence-based practice in provision of amplification. J Am Acad Audiol, Burlington, v. 16, n. 7, p. 419-438, Jul 2005.

DAVIDSON, L. S. et al. Factors contributing to speech perception scores in long-term pediatric Cl users. Ear Hear. v. 1, n. 32, p. 19s-26s, Feb 2011.

DAVIS, P. A. Effects of acoustic stimuli on the waking human brain. J Neurophysiol, v. 2, n. 6, p. 494-499, Nov 1939.

DEOUELL, L. Y.; BENTIN, S. Variable cerebral responses to equally distinct deviance in four auditory dimensions: a mismatch negativity study. Psychophysiology, v. 35, n. 6, p. 745-754, Nov 1998.

DESJARDIN, J. L. et al. Relationships between speech perception abilities and spoken language skills in young children with hearing loss. International Journal of Audiology, n. 48, p. 248-259, Nov 2009.

DORMAN, M. F. et al. Central auditory development: Evidence from CAEP measurements in children fit with cochlear implants. Journal of Communication Disorders, v. 40, n. 4, Jul-Aug 2007. 
EGGERMONT, J. J. et al. Maturational delays in cortical evoked potentials in cochlear implant users. Acta Oto-Laryngologica, v. 117, n. 2, Mar 1997.

FLEXER, C. Cochlear implans and neuroplasticity: linking auditory exposure and pratice. Cochlear Implants International, v. 12, n. S1, p. 19-21, 2011.

FRIESEN, L. M. et al. Evoked cortical activity and speech recognition as a function of the number of simulated cochlear implant channels. Clinical Neurophysiology, v. 120, n. 4, Apr 2009.

GANEK, H.; ROBBINS, A. M.; NIPARKO, J. K. Language Outcomes After Cochlear Implantation. Otolaryngologic Clinics of North America, v. 45, n. 1, Feb 2012.

GEERS, A. E. Factors affecting the development of speech, language, and literacy in children with early cochlear implantation. Language Speech and Hearing Services in Schools, v. 33, n. 3, Jul 2002.

GEERS, A. E. Speech, language, and reading skills after early cochlear implantation. Archives of Otolaryngology-Head \& Neck Surgery, v. 130, n. 5, May 2004.

GILLEY, P. M. et al. Developmental changes in refractoriness of the cortical auditory evoked potential. Clinical Neurophysiology, v. 116, n. 3, p. 648-657, Mar 2005.

GILLEY, P. M.; SHARMA, A.; DORMAN, M. F. Cortical reorganization in children with cochlear implants. Brain Research, v. 1239, p. 55-65, Nov 62008.

GORDON, K. A. Abnormal timing delays in auditory brainstem responses evoked by bilateral cochlear implant use in children. Otology \& Neurotology, v. 29, n. 2, Feb 2008.

GORDON, K. A.; TANAKA, S.; PAPSIN, B. C. Atypical cortical responses underlie poor speech perception in children using cochlear implants. Neuroreport, v. 16, n. 18, p. 2041-2045, Dec 192005.

GORDON, K. A. et al. Characterizing responses from auditory cortex in young people with several years of cochlear implant experience. Clin Neurophysiol, Amsterdam, v. 119, n. 10, p. 2347-2362, Oct 2008. 
GROENEN, P. A. P. et al. The relation between electric auditory brain stem and cognitive responses and speech perception in cochlear implant users. Acta OtoLaryngologica, v. 116, n. 6, Nov 1996.

GUIRAUD, J. et al. Effects of auditory pathway anatomy and deafness characteristics? Part 2: On electrically evoked late auditory responses. Hearing Research, v. 228, p. 44-57, 2007.

HANCOCK, K. E. et al. Neural coding of ITD with bilateral cochlear implants: Effects of congenital deafness. J Neurosci. v. 30, n. 42, p. 1-31, Oct 2010.

HAYES, H. et al. Receptive Vocabulary Development in Deaf Children with Cochlear Implants: Achievement in an Intensive Auditory-Oral Educational Setting. Ear and Hearing, v. 30, n. 1, Feb 2009.

JERGER, J. Clinical experience with impedance audiometry. Arch Otolaryngol, v. 92, n.4, p. 311-324, Oct. 1970.

JOHNSON, C. D. C. et al. Educational audiology handbook. In practices. San Diego: Singular Publishing Group, cap. 4, p. 49-371, 1997.

Assessment

JOHNSON, J. M. Late Auditory Event-Related Potentials in Children With Cochlear Implants: A Review. Developmental Neuropsychology, v. 34, n. 6, 2009.

KELLY, A. S.; PURDY, S. C.; THORNE, P. R. Electrophysiological and speech perception measures of auditory processing in experienced adult cochlear implant users. Clinical Neurophysiology, v. 116, n. 6, Jun 2005.

KILENY, P. R.; BOERST, A.; ZOWLAN, T. Cognitive evoked potentials to speech and tonal stimuli in children with implants. Otolaryngology-Head and Neck Surg, v. 117, n. 3, p. 161-169, Feb 1997.

KRAL, A.; EGGERMONT, J. J. What's to lose and what's to learn: Development under auditory deprivation, cochlear implants and limits of cortical plasticity. Brain Research Reviews, v. 56, p. 259-269, 2007.

KRAL, A.; SHARMA, A. Developmental neuroplasticity after cochlear implantation. Trends in Neurosciences, v. 35, n. 2, p. 111-122, Nov 2011. 
KURNAZ, M.; SATAR, B.; YETISER, S. Evaluation of cochlear implant users' performance using middle and late latency responses. Eur Arch Otorhinolaryngol, Heidelberg, v. 266, n. 3, p. 343-350, Mar 2009.

LIËGEOIS-CHAUVEL, C. et al. Evoked potentials recorded from the auditory cortex in man: evaluation and topography of the middle latency components. Electroencephalogr Clin Neurophysiol, v. 92, n. 3, p. 204-214, May 1994.

MARIAM, M. et al. Comparing the habituation of late auditory evoked potentials to loud and soft soud. Physiol Meas, v. 30, p. 141-153, 2009.

MARKMAN, T. M. et al. Language development after cochlear implantation: an epigenetic model. Journal of Neurodevelopmental Disorders, v. 3, n. 4, Dec 2011.

MAURER, J. et al. Auditory late cortical response and speech recognition in Digisonic cochlear implant users. Laryngoscope, v. 112, n. 12, p. 2220-2224, Dec 2002.

MCNEILL, C.; SHARMA, M.; PURDY, S. C. Are cortical auditory evoked potentials useful in the clinical assessment of adults with cochlear implants? Cochlear Implants Int, London, v. 10 Suppl 1, p. 78-84, 2009.

MCNEILL, C. et al. Cortical auditory evoked responses from an implanted ear after 50 years of profound unilateral deafness. Cochlear Implants Int, London, v. 8, n. 4, p. 189-199, Dec 2007.

MCPHERSON, D. L.; STARR, A. Auditory time-intensity cues in the binaural interaction component of the auditory evoked potentials. Hearing Research, v. 89, n. 1-2, p. 162-171, 1995.

MOOG, J. S.; GEERS, A. E. Speech and language acquisition in young children after cochlear implantation. Otolaryngologic Clinics of North America, v. 32, n. 6, Dec 1999.

MORET, A. L. M.; BEVILACQUA, M. C.; COSTA, O. A. Implante coclear: audição e linguagem em crianças deficientes auditivas pré-linguais. Pró-Fono R. Atual. Cient, v. 19, n. 3, p. 295-304, jul-set 2007.

NÄÄTÄNEN, R.; PICTON, T. The N1 wave of the human electric and magnetic response to sound: a review and an analysis of the component structure. Psychophysiology, v. 24, n. 4, p. 375-425. Jul 1987. 
NASCIMENTO, L. T.; BEVILACQUA, M. C. Avaliação da percepção da fala com ruído competitivo em adultos com implante coclear. Rev Bras Otorrinolaringol, v.71, n.4, p. 432-438, 2005.

NORTHERN, J. L.; DOWNS, M. P. Hearing in Children. Philadelphia: Lippincott, Williamn \& Wilkins, 5. Ed. 2002.

OKUSA, M. et al. Effects of discrimination difficulty on cognitive event-related brain potentials in patients with cochlear implants. Otolaryngol Head Neck Surg, v. 121, n. 5, p. 610-615, April 1999.

PANTEV, C. et al. Acoustically and electrically evoked responses of the human cortex before and after cochlear implantation. Hearing Research, v. 171, p. 191-195, 2002.

PETERSON, N. R.; PISONI, D. B.; MIYAMOTO, R. T. Cochlear implants and spoken language processing abilities: Review and assessment of the literature. Restorative Neurology and Neuroscience, v. 28, n. 2, p. 237-250, Jan 2010.

PISONI, D. et al. Article 7: Measures of digit span and verbal rehearsal speed in deaf children following more than 10 years of cochlear implantation. Ear Hear, v. 32, n. 1, p. 60-74, Fev 2011.

PONTON, C. W. et al. Auditory system plasticity in children after long periods of complete deafness. Neuroreport, v. 8, n. 1, Dec 201996.

PONTON, C. W.; EGGERMONT, J. J. Of kittens and kids: altered cortical maturation following profound deafness and cochlear implant use. Audiol. Neuro-otol, v. 6, p. 363-380, 2001.

PONTON, C. W.; MOORE, J. K.; EGGERMONT, J. J. Auditory brain stem response generation by parallel pathways: Differential maturation of axonal conduction time and synaptic transmission. Ear and Hearing, v. 17, n. 5, Oct 1996.

REYNELL, J. K.; GRUBER, C. P. Reynell developmental language scales. Los Angeles: Western Psychological Services. 1990.

ROMAN, S. et al. Relationship between auditory perception skills and mismatch negativity recorded in free field in cochlear-implant users. Hearing Research, v. 201, n. 1-2, p. 10-20, Mar 2005. 
SHALLOP, J. K. Objective Electrophysiological Measures from Cochlear Implant Patients. Ear and Hearing, v. 14, n.1, Feb 1993.

SHARMA, A.; DORMAN, M. F.; KRAL, A. The influence of a sensitive period on central auditory development in children with unilateral and bilateral cochlear implants. Hearing Research, v. 203, n. 1-2, p. 134-43, May 2005.

SHARMA, A.; DORMAN, M. F.; SPAHR, A. I. Rapid development of cortical auditory evoked potentials after early cochlear implantation. NeuroReport, v.13, n.10, Jul 2002.

SHARMA, A. et al. Developmental changes in P1 and N1 central auditory responses elicited by consonant-vowel syllables. Electroenceph clin Neurophysiol, v. 104, p. 540-455, 1997.

SHARMA, A.; NASH, A. A.; DORMAN, M. Cortical development, plasticity and reorganization in children with cochlear implants. Journal of Communication Disorders, v. 42, n. 4, Jul-Aug 2009.

SHARMA, A. et al. Central Auditory Maturation and Babbling Development in Infants with Cochlear Implants. Arch Otolaryngol Head Neck Surg, v. 130, p. 511-516, 2004.

SINGH, S. et al. Event-Related Potentials in Pediatric Cochlear Implant Patients. Ear and Hearing, v. 25, n. 6, p. 598-610 Dec 2004.

SOUZA, L. C. A. et al. Eletrofisiologia da Audição e Emissões Otoacústicas: princípios e aplicações clínicas. 2ª ed. Ribeirão Preto: Ed. Novo Conceito. 2010.

SPENCER, L. J.; TOMBLIN, J. B. Evaluating Phonological Processing Skills in Children With Prelingual Deafness Who Use Cochlear Implants. Journal of Deaf Studies and Deaf Education, v. 14, n. 1, p. 1-21, April 2009.

STUCHI, R. F. et al. Linguagem oral de crianças com cinco anos de uso do implante coclear. Pró-Fono Rev de Atualização Científica, Barueri (SP), v. 19, n. 2, p. 167176, abr.-jun. 2007.

TANAMATI, L. F. Audição e inteligibilidade da fala de crianças após 10 anos da cirurgia de implante coclear. 2012. Tese (Doutorado em Fonoaudiologia) Faculdade de Odontologia de Bauru, Universidade de São Paulo, Bauru, 2012. 
TANAMATI, L. F.; COSTA, O. A.; BEVILACQUA, M. C. Resultados a longo prazo com o uso do implante coclear em crianças: revisão sistemática. Arquivos Int. Otorrinolaringol, v.15, n.3, p. 365-375, 2011.

VALENTE, S. L. O. L. Elaboração de listas de sentenças construídas na língua portuguesa. 1998. Dissertação (Mestrado em Fonoaudiologia) -Pontifícia Universidade Católica de São Paulo, São Paulo, 1998.

VentuRA, L. M. P. ; AlvaRenGA, K. F.; COStA FilHO, O. A. Protocolo para captação dos potenciais evocados auditivos de longa latência. Braz. J. Otorhinolaryngol, São Paulo, v.75, n.6, p. 879-883, Nov/Dec 2009.

VENTURA, L. M. P.; COSTA FILHO, O. A.; ALVARENGA, K. F. Central hearing system maturation in normally hearing children. Pró-Fono Revista de Atualização Científica, v. 21, n. 2, p. 101-106, May 2009.

WUNDERLICH, J. L.; CONE-WESSON, B. K.; SHEPHERD, R. Maturation of the cortical auditory evoked potential in infants and young children. Hearing Research, v. 212, n. 1-2, Feb 2006.

YEHUDAI, N. et al. Demographic Factors Influencing Educational Placement of the Hearing-Impaired Child With a Cochlear Implant. Otology \& Neurotology, v. 32, n. 6, Aug 2011.

YOON, P. J. Hearing Loss and Cochlear Implantation in Children. Advances in Pediatrics, v. 58, p. 277-296, 2011.

ZHANG, F. et al. The adaptive pattern of the auditory N1 peak revealed by standardized low-resolution brain electromagnetic tomography. Brain Research, v. 1400, p. 42-52, May 2011.

ZWOLAN, T. A. et al. Pediatric cochlear implant patient performance as a function of age at implantation. Otology \& Neurotology, v. 25, n. 2, Mar 2004. 
Apêndices 



APÊNDICE A - Caracterização da casuística quanto à latência e amplitude do componente $\mathrm{P}_{1}$ dos Potenciais Evocados Auditivos Corticais encontrados nos indivíduos do grupo experimental e grupo controle e Teste de Percepção da Fala.

Potenciais Evocados Auditivos Corticais

\begin{tabular}{|c|c|c|c|c|c|}
\hline \multicolumn{4}{|c|}{ Grupo Experimental } & \multicolumn{2}{|c|}{ Grupo Controle } \\
\hline ID & Lat. $P_{1}$ (ms) & Amp. $P_{1}(\mu V)$ & TPF & Lat. $P_{1}$ (ms) & Amp. $P_{1}(\mu V)$ \\
\hline 1 & 168 & 0,43 & $76 \%$ & 105 & 2,24 \\
\hline 2 & 146 & 4,69 & $97 \%$ & 92 & 4,66 \\
\hline 3 & 118 & 0,86 & $78 \%$ & 96 & 1,46 \\
\hline 4 & 119 & 3,23 & $68 \%$ & 110 & 2,69 \\
\hline 5 & 144 & 2,84 & $88 \%$ & 114 & 2,01 \\
\hline 6 & 157 & 0,42 & $53 \%$ & 92 & 6,54 \\
\hline 7 & 80 & 1,77 & $71 \%$ & 115 & 2,51 \\
\hline 8 & 90 & 4,62 & $82 \%$ & 86 & 4,87 \\
\hline 9 & 172 & 0,66 & $65 \%$ & 76 & 3,87 \\
\hline 10 & 145 & 0,99 & $89 \%$ & 85 & 3,09 \\
\hline 11 & 142 & 0,26 & $94 \%$ & 109 & 5,44 \\
\hline 12 & 88 & 2,70 & $62 \%$ & 86 & 4,78 \\
\hline 13 & 150 & 1,98 & $50 \%$ & 80 & 4,66 \\
\hline 14 & 149 & 2,03 & $83 \%$ & 71 & 5,77 \\
\hline 15 & 284 & 2,49 & $89 \%$ & 87 & 8,59 \\
\hline 16 & 114 & 1,89 & $47 \%$ & 101 & 3,19 \\
\hline 17 & 112 & 5,92 & $90 \%$ & 82 & 4,74 \\
\hline 18 & 105 & 0,66 & $76 \%$ & 80 & 3,09 \\
\hline 19 & 78 & 4,18 & $72 \%$ & 75 & 4,53 \\
\hline 20 & 135 & 1,22 & $82 \%$ & 81 & 2,9 \\
\hline 21 & 163 & 1,76 & $54 \%$ & 142 & 3,01 \\
\hline 22 & 156 & 1,21 & $73 \%$ & 77 & 4,48 \\
\hline 23 & 145 & 3,07 & $70 \%$ & 80 & 1,76 \\
\hline 24 & 133 & 2,25 & $50 \%$ & 96 & 3,48 \\
\hline 25 & 127 & 3,96 & $42 \%$ & 57 & 2,74 \\
\hline 26 & 93 & 1,68 & $85 \%$ & 85 & 2,15 \\
\hline 27 & 67 & 4,95 & $91 \%$ & 71 & 1,67 \\
\hline 28 & 202 & 4,08 & $59 \%$ & 71 & 3,45 \\
\hline 29 & 111 & 2,99 & $37 \%$ & 75 & 3,27 \\
\hline 30 & 107 & 1,66 & $49 \%$ & 75 & 3,16 \\
\hline
\end{tabular}




Anexos 


ANEXO A - Ofício de aprovação do projeto de pesquisa pelo Comitê de Ética em Pesquisa, da Faculdade de Odontologia de Bauru da Universidade de São Paulo (Processo no 042/2011).

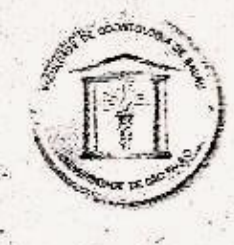

Processo $n=042 / 2011$

\section{Universidade de São Paulo \\ Faculdade de Odontologia de Bauru}

Al: Dr. Octávio Pinheiro Brisolia, 9-75-Bauru-SP-CEP 17012-901-C.P. 73

PABX (0XX14)3235-8000-FAX (0XX14)3223-4679

Conitê de Ética en Resquisa (14)3235-8356

e-mail: mferrari@fob.usp.br

Bauru, 28 de abril de 2011

Senhora Professora,

o projeto de pesquișa encaminhado a este Comitê de Ética em Pesquisa em Seres Humanos, denominado "Caracterizaçāo dos potenciais auditivos evacados de longa latência em crianças com vários anos de uso do implante coclear", de autoria de Raquel Caroline Ferreíra topes, que será desenvolvido sob sua orientação, foi enviado ao relator para avaliaçăo.

Na reuniảo de $\mathbf{2 7}$. de abril de $\mathbf{2 0 1 1}$ o parecter do relator, aprovando o projeto; foi aceito pelo comitề, considerando que nåo existem infroçōes éticas pendentes.

Informamos que qualł̧uer alteração efetuada no trabalho de pesquisa, o pesquisador/orientador deverá comunicar ao CEP-FOB/USP, bern como ao final do trabalho enviar um Relatório para novo parecer, o qual será utilizado para publicaçăo científica.

Atenciosamente,

$$
\text { Prof.Dr. Aávio Augusto Cardoso de Faria }
$$

Profa Dra Kátia de Freitas Alvarenga

Docente do Departamento de Fanoaudiología 
ANEXO B - Protocolo final do Comitê de Ética em Pesquisa, da Faculdade de

Odontologia de Bauru da Universidade de São Paulo (Processo no 042/2011).

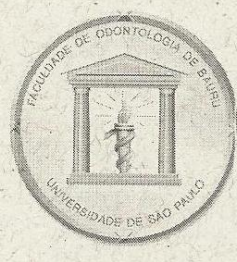

\section{Universidade de São Paulo \\ Faculdade de Odontologia de Bauru}

Comitê de Ética em Pesquisa

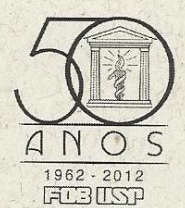

Proc. $N^{\circ} 042 / 2011$

Título do Projeto:

Caracterização dos potenciais auditivos evocados de longa latência (complexo

P1-N1-P2) em crianças com vários anos de uso de implante coclear.

Autor(es):

Raquel Caroline Ferreira Lopes e Profa. Dra. Adriane Lima Mortari Moret

Orientador(a):

Co-orientador(a)

Profa Dra Kátia de Freitas Alvarenga

Data de entrega do Relatório Final: 23 de janeiro de 2013

Data da reunião do CEP em que o 27 de fevereiro de 2013

Parecer Final será analisado:

$$
\text { A Aman }
$$

Secretária do Comitê de Ética em Pesquisa 
ANEXO C - Teste de percepção de fala: Sentenças CPA, Lista 2.

\section{LISTA DE SENTENÇAS - CPA - USP BAURU}

Número: Nome:

Data da avaliação:

Intensidade do sinal: Intensidade do ruído:

Relação S/R:

\section{L2 - Lista 2}

1. O menino chegou atrasado na escola.

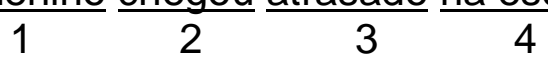

2. Meu dentista é muito calmo.

$$
5 \frac{1}{6} \frac{1}{8} \frac{}{9}
$$

3. Toda criança gosta de ganhar brinquedos.

$$
10 \frac{11}{12} \frac{13}{14}
$$

4. Dormi durante a viagem inteira.

$$
15 \frac{16}{17} \frac{18}{18}
$$

5. Domingo é dia de almoçar com a família reunida.

$$
1920 \frac{21}{22} \frac{23}{24} \frac{25}{25}
$$

6. Estou cansada de correr no parque.

$$
26 \frac{27}{28} \frac{19}{29}
$$

7. O Brasil tem cidades lindas para morar.

$$
30 \quad \frac{31}{32} \frac{13}{34} \frac{}{35}
$$

8. É perigoso dirigir com sono na estrada.

$$
36 \quad 37 \quad \frac{38}{39} \frac{40}{49}
$$

9. Eles foram para uma festa animada.

$$
\frac{11}{42} \frac{13}{44} \frac{15}{45}
$$

10. Aqueles homens pintaram a casa do prefeito.

$$
46 \frac{47}{48} \frac{a}{49}
$$

IRF = $X 2=$ $\%$ 
ANEXO D - Teste de percepção de fala: Sentenças CPA, Lista 3.

\section{LISTA DE SENTENÇAS - CPA - USP BAURU}

Número: Nome:

Data da avaliação:

Intensidade do sinal: Intensidade do ruído:

Relação S/R:

\section{L3 - Lista 3}

1. As pessoas estão poluindo o rio.

2. As férias de verão estão chegando.
5
78

3. O carro ficou mal estacionado na garagem.

$$
9 \quad 10 \quad 11 \quad 12 \quad 13
$$

4. Avisei para tomar cuidado com o cachorro bravo.

$14 \frac{16}{16} \frac{17}{18} \frac{19}{19}$

5. Gosto de ler romances policiais.
$20 \quad 21 \quad 22$
23

6. Gostaria de comer salada de alface fresquinha.

$$
24 \frac{25}{26} \frac{28}{26}
$$

7. Coração de mãe a gente não consegue esquecer nunca.

$$
29 \quad 30 \quad 31 \quad \frac{32}{33} \frac{34}{35}
$$

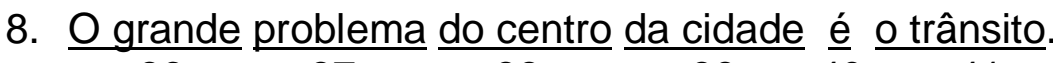

$36 \quad 37 \quad \frac{38}{40} \frac{31}{40}$

9. A professora mora na casa dos pais.

$$
42 \quad 43 \quad 44 \quad \frac{45}{4}
$$

10. A televisão quebrou durante a novela das oito.

$$
46 \quad \frac{47}{48} \frac{19}{50}
$$

IRF = $\mathbf{X} 2=$ $\%$ 